\title{
Critical Effect of Carbon Vacancies on the Reverse Water Gas Shift Reaction over Vanadium Carbide Catalysts
}

\author{
Arturo Pajares ${ }^{\mathrm{a}, \mathrm{b}, \boldsymbol{\oplus}}$, Hèctor Prats ${ }^{\mathrm{c}, \boldsymbol{f}}$, Alexandre Romero ${ }^{\mathrm{d}}$, Francesc Viñes ${ }^{\mathrm{c}, *}$, Pilar Ramírez de la \\ Piscina ${ }^{\mathrm{a},{ }^{*}, \text { Ramon Sayós }}{ }^{\mathrm{c}}$, Narcís Homs ${ }^{\mathrm{a}, \mathrm{b}}$, and Francesc Illas ${ }^{\mathrm{c}}$ \\ ${ }^{a}$ Departament de Química Inorgànica i Orgànica, Secció de Química Inorgànica and Institut de Nanociència i \\ Nanotecnologia (IN2UB), Universitat de Barcelona, Martí i Franquès 1-11, \\ 08028 Barcelona, Spain. \\ ${ }^{\mathrm{b}}$ Catalonia Institute for Energy Research (IREC), Jardins de les Dones de Negre 1, \\ 08930 Barcelona, Spain \\ ${ }^{\mathrm{c} D e p a r t a m e n t ~ d e ~ C i e ̀ n c i a ~ d e ~ M a t e r i a l s ~ i ~ Q u i ́ m i c a ~ F i ́ s i c a ~ \& ~ I n s t i t u t ~ d e ~ Q u i ́ m i c a ~ T e o ̀ r i c a ~ i ~ C o m p u t a c i o n a l ~(I Q T C U B), ~}$ \\ Universitat de Barcelona, Martí i Franquès 1-11, \\ 08028 Barcelona, Spain. \\ ${ }^{\mathrm{d}}$ École Nationale Supérieure des Ingénieurs en Arts Chimiques et Technologiques (INP-ENSIACET), 4 Allée Emile \\ Monso, 31030 Toulouse, France.
}

\footnotetext{
*Corresponding authors: Francesc Viñes (francesc.vines@ub.edu), Pilar Ramírez de la Piscina (pilar.piscina@qi.ub.edu)
}

Keywords: vanadium carbide; carbon vacancies; reverse water gas shift; $\mathrm{CO}_{2}$ utilization, heterogeneous catalysis; density functional calculations

\begin{abstract}
Experimental and theoretical evidences show that carbon vacancies determine the catalytic behavior of vanadium carbides in the $\mathrm{CO}_{2}$ conversion to $\mathrm{CO}$ via the Reverse Water Gas Shift (RWGS) reaction. Two $\mathrm{VC}_{\mathrm{x}}$ samples, one mostly containing stoichiometric $\mathrm{VC}$ and the other being $\mathrm{C}$ deficient, mainly $\mathrm{V}_{8} \mathrm{C}_{7}$, were synthesized, characterized, and studied. The samples show different $\mathrm{CO}_{2}$ adsorption heats, which correlate with those calculated using Density Functional Theory (DFT) on suitable models. The sample containing more $\mathrm{V}_{8} \mathrm{C}_{7}$ shows a higher $\mathrm{CO}_{2}$ conversion and $\mathrm{CO}$ selectivity and a lower apparent activation energy, being a stable catalyst over long-time tests. DFT calculations confirm that $\mathrm{C}$ vacancies in $\mathrm{V}_{8} \mathrm{C}_{7}$ are responsible for the observed catalytic behavior, allowing reactants to adsorb more strongly, lowering the energy barrier for both $\mathrm{H}_{2}$ and $\mathrm{CO}_{2}$ dissociation steps. The present work highlights the importance of such native point defects in the transition metal carbides surface chemistry and catalytic properties.
\end{abstract}




\section{Introduction}

The industrial utilization of $\mathrm{CO}_{2}$ as a carbon source for chemical processes is appealing from the environmental point of view, with obvious benefits removing the main greenhouse gas causing global warming and, at the same time, constituting an abundant and cheap $\mathrm{C}_{1}$ chemical feedstock. Thus, it is no strange that, nowadays, great research endeavors are addressed towards the $\mathrm{CO}_{2}$ chemistry, with emphasis on the chemical conversion of $\mathrm{CO}_{2}$ by heterogeneous catalysis [1]. However, this overall process requires materials able to capture the gas $\mathrm{CO}_{2}$, through the so-known Carbon Capture and Storage (CCS) technologies [2,3]. Ideally, such a scrubber material would not only sequester $\mathrm{CO}_{2}$ but as well promote its chemical activation thus constituting a possible useful candidate material for Carbon Capture and Utilization (CCU) technologies [2-5], allowing a simplified potential industrial setup. Along these lines, the Reverse Water Gas Shift (RWGS) reaction $\left(\mathrm{CO}_{2}+\mathrm{H}_{2} \rightarrow \mathrm{CO}+\mathrm{H}_{2} \mathrm{O} ; \Delta_{r} H^{o}=41.2 \mathrm{~kJ} \mathrm{~mol}^{-1}-0.43 \mathrm{eV}\right.$ - at $\left.298 \mathrm{~K}\right)$ [6] has gained momentum towards the utilization of $\mathrm{CO}_{2}$ as an economic $\mathrm{C}_{1}$ carbon source, e.g. for synthetic fuel production [7]. After water separation, the RWGS generated $\mathrm{CO}$ can be used, within a $\mathrm{CO} / \mathrm{CO}_{2} / \mathrm{H}_{2}$ mixture, as synthesis gas (syngas) for the Fischer-Tropsch or methanol synthesis to obtain hydrocarbons and/or alcohol fuels [8]. Within these premises, the RWGS coupled to a sustainable source of energy for the reaction requirements - i.e. renewable $\mathrm{H}_{2}$ production- could be introduced as a fundamental gear to close the C-cycle.

Recently, Density Functional Theory (DFT) based calculations have predicted that early Transition Metal Carbides (TMCs) are possible highly-active, resilient, and economic materials for CCS technologies, even at stringent conditions of temperature and $\mathrm{CO}_{2}$ partial pressure [9]. Such TMCs are long-regarded in the literature as alternative materials to Pt-group transition metal-based catalysts, with similar or even higher catalytic activities and selectivities [10], very high chemical and physical resistances [11], and even being typically S- and C-poisoning resistant [12-15]. At variance with Pt-group transition metals, the strong $\mathrm{CO}_{2}$ adsorption on the different TMCs can even allow their use in chemical resolution processes, such as the separation of $\mathrm{CH}_{4}$ and $\mathrm{CO}_{2}$ in biogas upgrading processes [16]. These computational simulations forecasted that some of these TMCs, such as $\mathrm{ZrC}$ and $\mathrm{HfC}$, would be able to capture $\mathrm{CO}_{2}$ even at $473 \mathrm{~K}$ from sources with a low $\mathrm{CO}_{2}$ content, such as atmospheric air, with a current $\mathrm{CO}_{2}$ partial pressure, $p_{\mathrm{CO}_{2}}$, of $40.5 \mathrm{~Pa}$ [17]. The theoretical predictions became afterwards experimentally confirmed on $\mathrm{TiC}, \mathrm{ZrC}$, and $\mathrm{VC}$ samples [18]. Further, several TMCs were found to be able to activate $\mathrm{CO}_{2}$, resulting in a partially negatively charged bent molecular species. This added up to the point that such TMCs are able to 
attach $\mathrm{H}_{2}$ and split it [19-21], allows considering them as viable catalysts for $\mathrm{CO}_{2}$ hydrogenation reactions [22].

In principle, activated $\mathrm{CO}_{2}$ can evolve to $\mathrm{CO}$ although this constitutes the main rate-limiting step of the RWGS. In this context, several TMCs have been proposed as economic alternative catalysts to current $\mathrm{Pt} / \mathrm{CeO}_{2}$ for the RWGS [23] since TMCs materials seem to be able to reduce the $\mathrm{CO}_{2}$ dissociation step energy barrier [24]. From a theoretical point of view, $\delta$-MoC and $\alpha$ - and $\beta$ $\mathrm{Mo}_{2} \mathrm{C}$ have been the most studied TMCs for $\mathrm{CO}_{2}$ reduction [24-27], where the Mo:C ratio has been often argued as being a critical aspect of the material surface chemistry and catalytic behaviour $[28,29]$. Similarly, in a recent study, the $\mathrm{W}: \mathrm{C}$ ratio of tungsten carbides embedded in carbon spheres ( $\mathrm{W}_{\mathrm{x}} \mathrm{C} @ \mathrm{CS}$ ) was found to directly affect the guaiacol to phenol production and selectivity by hydrogenolysis [30]. Even though TMCs are known to display a certain quantity of C vacancies, up to the point that sub-stoichiometric phases are common $[31,32]$, most of the previous catalytic studies dealt with idealized stoichiometric TMC phases. Inspired by the key role that oxygen vacancies play in the catalytic behaviour of transition metal oxides [33,34], and by recent findings showing that the Strong Metal Support Interaction (SMSI) concept [35,36] can be extended from metal/oxide to metal/carbide catalysts [37], disclosing the effects that $\mathrm{C}$ vacancies may have on the catalytic behaviour of TMCs appears mandatory. In this respect, it has been claimed that, given the difficulty of gaining the significance of defect chemistry in TMCs by solely experimental studies [38], theoretical simulations constitute a complementary powerful tool.

Here, a combination of experiments and computational models are applied to the study of the mechanism of the RWGS catalysed by vanadium carbide. VC has been selected because, compared to other TMCs, it displays a low affinity for oxygen [39-41], thus preventing the easy formation of oxycarbides. Furthermore, earlier DFT calculations showed that the hybridization between $\mathrm{V} d$ and $\mathrm{C} p$ orbitals yields hydrogen binding energies comparable to $\mathrm{Mo}_{2} \mathrm{C}$ and WC yet slightly smaller $[19,22,42]$. The small O affinity of VC anticipates a poor RWGS catalytic activity, destabilizing the adsorbed $\mathrm{O}$ adatom intermediate state formed during the $\mathrm{CO}_{2}$ reduction to $\mathrm{CO}$. Surprisingly, $\mathrm{VC}_{\mathrm{x}}$ samples, here prepared using a novel sol-gel method, reveal a good catalytic performance in the RWGS reaction. This unforeseen behaviour is here explained on the basis of reaction profiles obtained from DFT-based calculations revealing the key role played by surface C vacancies. Interestingly, this reaction is barely feasible when $\mathrm{C}$ vacancies are not present. In short, the present work provides compelling evidence of the paramount role that $\mathrm{C}$ vacancies have in determining the surface chemistry and the concomitant catalytic behaviour of VC, likely to affect the chemistry of other TMC materials. Thus, the present findings highlight the importance of such native point defects in determining the overall chemistry and catalytic properties of TMC surfaces, 
showing how and why the presence of vacancies completely determines the resulting catalytic behaviour.

\section{Experimental Section}

\subsection{Catalyst preparation}

We studied the preparation of $\mathrm{VC}_{\mathrm{x}}$ phases applying a gel-like method and using 4,5dicyanoimidazole as carbon precursor and $\mathrm{VOCl}_{3}$ or $\mathrm{VO}$ (isopropoxide) $)_{3}$ as vanadium precursors. $\mathrm{A}$ summary of the synthesis is given in Section S1 of the Supplementary Material. Among all the prepared samples, VC-1 and VC-2 were specifically chosen for this work. Briefly, for the preparation of $\mathrm{VC}-1,7.96 \mathrm{mmol}$ of $\mathrm{VOCl}_{3}$ were dissolved into $15 \mathrm{~mL}$ of ethanol, and then 7.96 mmol of 4,5-dicyanoimidazole were added. The solution was kept under continuous stirring at room temperature under Ar and afterwards ethanol was evaporated to produce a gel. The sample was treated in a tubular furnace under Ar flow up to $1373 \mathrm{~K}\left(2.5 \mathrm{~K} \cdot \mathrm{min}^{-1}\right)$ for $5 \mathrm{~h}$; then cooled down to room temperature under Ar and exposed to room ambient without passivation. The VC-2 sample was similarly prepared using $7.96 \mathrm{mmol}$ of $\mathrm{VO}$ (isopropoxide) $)_{3}$ and $10.75 \mathrm{mmol}$ of 4,5dicyanoimidazole. The preparation method used is inspired in the soft-urea pathway but using 4,5dicyanoimidazole as carbon source [43]. The initial gel condenses during the thermal treatment with the formation of an intermediate glass. The composition of this intermediate material, which depends on the metal and carbon precursors and the carbon precursor/metal precursor ratio, is expected to influence the final material obtained $[43,44]$. After preparation, samples were not passivated because a detrimental effect of the $\mathrm{O}_{2}$ passivation in the activity of alumina-supported molybdenum carbide catalysts for $\mathrm{CO}_{2}$ hydrogenation has been found [45]. It seems that is easier to control the extent of oxidation when mild oxidants such as $\mathrm{CO}_{2}$ or $\mathrm{H}_{2} \mathrm{O}$ are used $[46,47]$.

\subsection{Characterization}

$\mathrm{N}_{2}$ adsorption-desorption isotherms were carried out at $77 \mathrm{~K}$ using a Micromeritics Tristar II 3020 instrument. The specific surface area $\left(\mathrm{S}_{\mathrm{BET}}\right)$ was calculated by multipoint analysis of $\mathrm{N}_{2}$ adsorption isotherms. The pore size distribution was calculated applying the BJH method. Powder X-ray diffraction patterns (XRD) were collected between $2 \theta=20^{\circ}-100^{\circ}$, with a step width of $0.017^{\circ}$ and counting $80 \mathrm{~s}$ at each step, using a PANalytical X'Pert PRO MPD Alpha1 powder diffractometer, focalizing $\mathrm{Ge}(111)$ primary monochromator and $\mathrm{Cu} \mathrm{K \alpha} 1$ radiation source $(\lambda=1.5406 \AA)$. The mean crystallite size of $\mathrm{VC}_{\mathrm{x}}$ phases were calculated using the Debye-Scherrer equation. Scanning Transmission Electron Microscopy (STEM) images were acquired using a JEOL JEM-2100 LaB6 
transmission electron microscope, operating at $200 \mathrm{kV}$ in STEM mode, using the high angle annular dark field detector; the beam size was around $15 \mathrm{~nm}$. Energy Dispersive X-ray (EDX) analysis was performed with an Oxford Instruments INCA x-sight, with Si (Li) detector coupled to the STEM system. Map acquisition was accomplished using the INCA Microanalysis Suite version 4.09 software.

Transmission Electron Microscopy (TEM) images and the phase mapping of samples were collected employing a JEOL J2010F microscope operated at an accelerating voltage up to $200 \mathrm{kV}$. To obtain a reliable phase map at the nanometric scale we used the electron beam precession in TEM analysis together with spot Precession Electron Diffraction (PED) pattern recognition, commercial ASTAR ${ }^{\mathrm{TM}}$ technique [48-50]. Maps were acquired using a step size of 5 or $10 \mathrm{~nm}$. The precession unit was operated at $100 \mathrm{~Hz}$, acquiring 5 frames per second and using a precession angle of $1^{\circ}$. PED patterns were recorded with an ultrafast external camera (Stingray F-046 Allied Visions) and used for the crystal phase mapping construction. The distortions in the diffraction patterns introduced by the external position of the camera were corrected during the data treatment.

$\mathrm{H}_{2}$-Temperature Programmed Reduction $\left(\mathrm{H}_{2}\right.$-TPR) experiments were carried out using a Micromeritics AutoChem II 2920 chemisorption equipment. Samples were pretreated at 363 K under $\mathrm{He}$ and then, exposed to $\mathrm{a}_{2} / \mathrm{Ar}(12 \% \mathrm{v} / \mathrm{v})$ flow, the temperature was increased up to $1073 \mathrm{~K}$ at $10 \mathrm{~K} \cdot \mathrm{min}^{-1}$. X-ray Photoelectron Spectroscopy (XPS) analysis was performed using a Perkin Elmer PHI-5500 Multitechnique System (Physical Electronics) with an Al X-ray source (hv= $1486.6 \mathrm{eV}$ and $350 \mathrm{~W}$ ). Samples were kept in an ultra-high vacuum chamber during data acquisition $\left(5 \cdot 10^{-9}-2 \cdot 10^{-8}\right.$ Torr). Using Au as reference, the Binding Energy (BE) of C $1 s$ at $284.8 \mathrm{eV}$, attributed to adventitious carbon, was determined. This signal was used as reference for the determination of all the others BE values. Raman spectra were collected using a Jobin-Yvon LabRam HR 800, with an optical Olympus BXFM microscope, a $532 \mathrm{~nm}$ laser and a CCD detector. The laser power was limited to $0.75 \mathrm{~mW}$ to reduce laser-heating effects during spectra acquisition.

Thermogravimetric and calorimetric analysis, applied to study the $\mathrm{CO}_{2}$ adsorption onto the catalysts and the reactivity of $\mathrm{CO}_{2}$ with the catalysts, were carried out using a Sensys Evo TG-DSC instrument (Setaram), equipped with a 3D thermal flow sensor, coupled to a Pfeiffer Mass Spectrometer (MS). For $\mathrm{CO}_{2}$ adsorption, catalysts $(50 \mathrm{mg})$ were firstly dried in Ar flow at $353 \mathrm{~K}$, then heated up to $823 \mathrm{~K}\left(10 \mathrm{~K} \cdot \mathrm{min}^{-1}\right)$ under a $\mathrm{H}_{2} / \mathrm{Ar}$ flow $(10 \% \mathrm{v} / \mathrm{v})$ for $1 \mathrm{~h}$, and finally cooled down to $303 \mathrm{~K}$ for $\mathrm{CO}_{2}$ chemisorption. In separate experiments, the reactivity of catalysts with $\mathrm{CO}_{2}$ was studied at $873 \mathrm{~K}$. Dry samples were heated up to $873 \mathrm{~K}$ at $10 \mathrm{~K} \cdot \mathrm{min}^{-1}$ under flowing $\mathrm{CO}_{2} / \mathrm{Ar}$ $(10 \% \mathrm{v} / \mathrm{v})$; then, after $3 \mathrm{~h}$ at $873 \mathrm{~K}$, cooled down at room temperature, and further characterized. The presence of CO in the outflow was determined by MS analysis. 


\subsection{RWGS catalytic tests}

RWGS tests were performed in a Microactivity-Reference unit (PID Eng\&Tech). A tubular fixedbed 316-L stainless steel reactor (305 $\mathrm{mm}$ long, $9 \mathrm{~mm}$ i.d,) with a thermocouple in direct contact with the catalytic bed was used. In all cases, $150 \mathrm{mg}$ of catalyst and a catalytic bed of $1 \mathrm{~mL}$ were utilized; silicon carbide was used as diluting agent. The fresh catalyst was heated from room temperature up to $573 \mathrm{~K}$ under $\mathrm{N}_{2}$ flow and then, exposed to a reactant gas mixture of $\mathrm{CO}_{2} / \mathrm{H}_{2} / \mathrm{N}_{2}=$ 1/3/1 (mol/mol) under a Gas Hourly Space Velocity (GHSV) of $3000 \mathrm{~h}^{-1}$. The catalytic behavior in the RWGS was studied between $573 \mathrm{~K}$ and $873 \mathrm{~K}$ at $0.1 \mathrm{MPa}$. The long-term catalytic test (about four days) was carried out at $723 \mathrm{~K}$, using $300 \mathrm{mg}$ of catalyst and keeping all the other reaction conditions. The products were analyzed online with a Varian 450-GC-MS equipped with a TCD, two FID and a mass detector. Only $\mathrm{CO}$ and $\mathrm{CH}_{4}$ were found as products. The carbon balance between the outlet gas and the reactant inlet was $\leq 1 \% . \mathrm{CO}_{2}$ conversion and product distribution were determined at each temperature by the average of at least 4 different analyses. The $\mathrm{CO}_{2}$ conversion $\left(\mathrm{X}_{\mathrm{CO}_{2}}\right)$ and the selectivity to the $i$ product $\left(S_{i}\right)$ were defined and obtained as follows:

$$
\begin{gathered}
X_{\mathrm{CO}_{2}}(\%)=\left(1-\frac{\left(C_{\mathrm{CO}_{2}}\right)_{\text {outlet }}}{\left(C_{\mathrm{CO}_{2}}\right)_{\text {outlet }}+\sum\left(C_{i}\right)_{\text {outlet }}}\right) \cdot 100 \\
S_{i}(\%)=\frac{\left(C_{i}\right)_{\text {outlet }}}{\sum\left(C_{i}\right)_{\text {outlet }}} \cdot 100
\end{gathered}
$$

where $\left(C_{i}\right)$ and $C_{\mathrm{CO}_{2}}$ are the molar concentration of the $i$ product $\left(\mathrm{CO}\right.$ or $\left.\mathrm{CH}_{4}\right)$ and $\mathrm{CO}_{2}$, respectively.

\section{Computational methods}

Periodic spin-polarized DFT based calculations have been carried out using the Vienna Ab Initio Simulation Package (VASP) code [51]. The Perdew-Burke-Ernzerhof (PBE) exchange-correlation (xc) functional has been chosen [52], and dispersion - van der Waals - interactions have been included through the D3 method as proposed by Grimme and coworkers [53]. The PBE-D3 calculated energy differences are accurate enough to properly describe the interaction of reactants, intermediates, and products on TMC systems, as proven in the past on joint experimental and theoretical works [18-20,24,27]. The valence electron density has been expanded in a plane wave basis set with a kinetic energy cutoff of $415 \mathrm{eV}$. The effect of core electrons on the valence electron density is described by the Projector Augmented Wave (PAW) method of Blöchl [54], as 
implemented by Kresse and Joubert [55]. The gas-phase energy of a species $i, E_{i}$, is gained by placing the gas molecule and optimizing its structure in an asymmetric box of $9 \times 10 \times 11 \AA$ at the $\Gamma$ point. A $9 \times 9 \times 1$ Monkhorst-Pack [56] scheme k-point mesh has been used in all the slab calculations, whose geometries have been optimized prior to the placing of any adsorbate. Initial guesses for adsorbate geometries were obtained by placing the adsorbate at different sites, see Figure 1.

The surface slab models have been constructed for the $\mathrm{VC}(001)$ surface, experimentally known to be the most stable and, hence, dominant surface in samples of rocksalt TMCs, but also confirmed based on theoretical estimates of surface energies, which point out such surface being, to a large extent, the most exposed, as expected from the Wulff construction minimizing the overall material surface tension $[11,57,58]$. The slab models have been built from a previously optimized bulk unit cell and contain four atomic layers, where the bottom two have been constrained to bulk positions to provide the appropriate environment to the two uppermost surface atomic layers, whose atomic structure has been fully relaxed [9]. To avoid interactions between the periodically interleaved slabs, a vacuum region of $12 \AA$ perpendicular to the surface has been added. The structure of all adsorbates has been relaxed to find their optimum geometry using a conjugategradient algorithm, with an energy convergence criterion for electronic updates of $10^{-5} \mathrm{eV}$, and an atomic force convergence criterion of $0.02 \mathrm{eV} \AA^{-1}$. The optimized geometries have been characterized as minima in the potential energy surface by frequency analysis with $0.03 \AA$ finite displacements.

The VC(001) surface slab model used in the present work consists of a $(2 \sqrt{2} \times 2 \sqrt{ } 2) \mathrm{R} 45^{\circ}$ surface unit cell, having a total of $32 \mathrm{~V}$ and $32 \mathrm{C}$ atoms, see Figure 1 whereas a second system corresponding to $\mathrm{VC}(001)$ with a surface $\mathrm{C}$ vacancy, labelled VC-vac, was constructed to model the $\mathrm{V}_{8} \mathrm{C}_{7}(001)$ phase. This choice is reasonable, since the optimized lattice parameters for both VC and $\mathrm{V}_{8} \mathrm{C}_{7}$ are identical. The only difference among these bulk structures arises from the presence of extra $\mathrm{C}$ vacancies in $\mathrm{V}_{8} \mathrm{C}_{7}$ at the subsurface and inner layers in an ordered manner. However, the $\mathrm{C}$ defective sites at the surface are the only ones strongly affecting the catalytic properties of the material. Therefore, adsorption energies and energy barriers on $\mathrm{V}_{8} \mathrm{C}_{7}$ can be obtained from a system consisting on VC with a surface C vacancy. Further details regarding the validity of using VC(001) with a surface $\mathrm{C}$ vacancy to model the $\mathrm{V}_{8} \mathrm{C}_{7}(001)$ are provided in the Supplementary Material, section S2, Figures S1 and S2 and Table S1. For final geometries, the adsorption energy of a species $i, \Delta_{a d s} E_{A}^{Z P E}$, is then calculated as:

$$
\Delta_{a d s} E_{i}^{Z P E}=E_{i, s l a b}-\left(E_{\text {slab }}+E_{i}\right)+E_{Z P E}
$$


where $E_{i, s l a b}$ is the energy of the species $i$ adsorbed on the corresponding slab model, $E_{\text {slab }}$ is the energy of the relaxed pristine slab, $E_{i}$ is the energy of an isolated molecule of species $i$, and $E_{Z P E}$ is the Zero Point Energy (ZPE) term, calculated considering both gas phase and adsorbed phase within the harmonic approximation, with Hessian matrix elements obtained from finite differences of analytical gradients with displacements of $0.03 \AA$.

Finally, Transition State (TS) structures were located by using the Climbing-Image Nudged Elastic Band (CI-NEB) method [59]. The initial guesses for the employed four intermediate images were generated by means of the Atomic Simulation Environment (ASE) [60] package using the Image Dependent Pair Potential (IDPP) procedure [61]. The obtained TS candidates have been characterized by a proper vibrational analysis, vide supra. The potential energy reaction profiles correspond to $0 \mathrm{~K}$ and in vacuum pressure conditions. To account for temperature and pressure effects, the free energy reaction profiles have been acquired at the catalytic working conditions of temperature $(873 \mathrm{~K})$ and reactant pressures $\left(p_{\mathrm{CO}_{2}}=20 \mathrm{kPa}, p_{\mathrm{H}_{2}}=60 \mathrm{kPa}\right)$ by using the atomistic statistical thermodynamics approach [62], see details in the Supplementary Material.

\section{Results and discussion}

Both VC-1 and VC-2 are mesoporous materials with average pore widths of 5.0 and $3.4 \mathrm{~nm}$, and $\mathrm{S}_{\mathrm{BET}}$ of 204 and $315 \mathrm{~m}^{2} \mathrm{~g}^{-1}$, respectively. The XRD analysis (see Figure S3) indicates the presence of cubic VC (JCPDS 01-073-0476) and/or C-defective $\mathrm{V}_{8} \mathrm{C}_{7}$ (JCPDS 00-035-0786) phases for both VC-1 and VC-2, being the VC-2 crystallinity lower than that of VC-1. The calculated crystallite sizes are 64 and $10 \mathrm{~nm}$ for $\mathrm{VC}-1$ and $\mathrm{VC}-2$, respectively. The TEM and HRTEM analyses in Figures $2 \mathrm{~A}$ and $3 \mathrm{~A}$ confirm the presence of smaller $\mathrm{VC}_{\mathrm{x}}$ particles in $\mathrm{VC}-2$ (mean size of $7.0 \mathrm{~nm}$ ) than in VC-1 (mean size of $64.1 \mathrm{~nm}$ ). In both cases, STEM-EDX analysis shows a homogeneous distribution of vanadium along the samples, see Figures $2 \mathrm{~B}$ and $3 \mathrm{~B}$. VC-1 and VC-2 were analyzed in different zones by means of PED with spot electron diffraction-pattern recognition (PEDASTAR). Experimental ED patterns of different zones were indexed according to $\mathrm{V}_{8} \mathrm{C}_{7}$ and $\mathrm{VC}$, the best fitting indexation was used to obtain a reliable nanoscale phase mapping (Figures S4 and S5). In general, from PED-ASTAR analysis the major presence of VC phase can be deduced in VC-1, see Figure 2C. On the contrary, for VC-2, most of the analyzed zones showed a better fitting indexation when the presence of $\mathrm{V}_{8} \mathrm{C}_{7}$ is assumed, see Figure $3 \mathrm{C}$.

Both samples show low intensity Raman bands centered at $1358 \mathrm{~cm}^{-1}$ and $1595 \mathrm{~cm}^{-1}$ (see Figure S6), reasonably assigned to the presence of residual amorphous carbon. Moreover, VC-1 shows several bands in the $100-1100 \mathrm{~cm}^{-1}$ region related to surface oxy-vanadium species, likely 
formed when the samples were exposed to air [39-41]. The very low intensity band at $991 \mathrm{~cm}^{-1}$ indicates that, if any, the amount of crystalline $\mathrm{V}_{2} \mathrm{O}_{5}$ is very low [63-65]. The $\mathrm{VC}-2$ presents much lower intense Raman bands in the $100-1100 \mathrm{~cm}^{-1}$ region than VC-1 (Figure S6), which would be related with the presence of a lower amount of surface oxy-vanadium species. The $\mathrm{H}_{2}$-TPR profile of VC-1 (see Figure S7) indicates a small $\mathrm{H}_{2}$ consumption at $743 \mathrm{~K}\left(0.77 \mathrm{mmol} \mathrm{H} \cdot \mathrm{g}_{\text {cat }}{ }^{-1}\right)$, attributed to the reduction of mono-or polymeric oxy-vanadium (V) species; note that the reduction of amorphous $\mathrm{V}_{2} \mathrm{O}_{5}$ would take place at $\sim 852 \mathrm{~K}$ and that of crystalline $\mathrm{V}_{2} \mathrm{O}_{5}$ at higher temperatures $[64,66]$. The low $\mathrm{H}_{2}$ consumption $\left(0.41 \mathrm{mmol} \mathrm{H}_{2} \mathrm{~g}_{\mathrm{cat}}{ }^{-1}\right)$ of $\mathrm{VC}-2$ at $528 \mathrm{~K}$ can be reasonably related to the reduction of vanadium oxycarbide species, as has been proposed for $\mathrm{MoC}_{\mathrm{x}}$ systems [24].

The two catalysts were further analyzed by XPS. Figures $4 \mathrm{~A}$ and $5 \mathrm{~A}$ show the $\mathrm{V} 2 p$ and $\mathrm{C}$ $1 s$ core level spectra, respectively. The V $2 p$ spectra can be deconvoluted into 3 doublets (V $2 p_{3 / 2}$ $\left.\mathrm{V} 2 p_{1 / 2}\right)$. The analysis of $\mathrm{V} 2 p_{3 / 2}$ level with the corresponding bands centered at 513.6-513.8, 514.5514.9, and 516.5-517.3 eV, clearly indicates the coexistence on the surface of vanadium carbide and different types of $\mathrm{V}^{\mathrm{n}+}-\mathrm{O}$ species, the latter corresponding to the two higher binding energy features [67-69]. The C $1 s$ spectra of both VC-1 and VC-2 samples show a broad peak with maximum at $284.8 \mathrm{eV}$, the features at 282.9-283.0 eV are assigned to $\mathrm{V}-\mathrm{C}$ species [67,68,70]; the shoulders at $\mathrm{BE}$ higher than $284.8 \mathrm{eV}$ are related to the presence of $\mathrm{C}-\mathrm{O}, \mathrm{C}=\mathrm{O}$ and $\mathrm{O}=\mathrm{C}-\mathrm{O}$ groups [71-73]. Consistent with this assignment, wide $\mathrm{O} 1 s$ peaks were found (Figure S8A), being the component at lower BE (530.0-530.4 eV) assigned to oxy-species of vanadium and that at 531.3-531.5 eV to $\mathrm{OH}$ and/or oxycarbide species; components at higher BE are attributed to different oxygen-carbon bonded species $[18,67,74]$. On the other hand, XPS signals related to the presence of N-containing species were not found (Figure S9A), indicating that $\mathrm{N}$ coming from the 4,5-dicyanoimidazole used as $\mathrm{C}$-precursor was eliminated during the $\mathrm{VC}_{\mathrm{x}}$ preparation, discarding the presence of vanadium nitride species.

The $\mathrm{CO}_{2}$ adsorption, which is a determining step of the RWGS, was studied on both samples, VC-1 and VC-2, by calorimetry. The experimental mean adsorption heat of $\mathrm{CO}_{2}$ on $\mathrm{VC}-2$ is $-0.54 \mathrm{eV}$, much higher than on $\mathrm{VC}-1$, having a value of $-0.25 \mathrm{eV}$. Furthermore, the amount of $\mathrm{CO}_{2}$ adsorbed on $\mathrm{VC}-2,0.074 \mathrm{mg} \mathrm{CO} \mathrm{mg}_{\mathrm{cat}}{ }^{-1}$, is slightly higher than that on $\mathrm{VC}-1,0.059 \mathrm{mg} \mathrm{CO}_{2}$ $\mathrm{mg}_{\mathrm{cat}}{ }^{-1}$. Keeping in mind that the experimental mean adsorption heats involve a diversity of adsorptive situations, the experimental values of $\mathrm{CO}_{2}$ adsorption heat correlate quite well with the DFT estimates of -0.85 and $-0.18 \mathrm{eV}$ for VC with $\mathrm{C}$ vacancy, VC-vac, and VC models, respectively (see Table S2 in Supplementary Material). In any case, the differences of adsorption heats seem to correlate well with VC-2 sample having much more $\mathrm{C}$ vacancies, which in turn corresponds with that of $\mathrm{V}_{8} \mathrm{C}_{7}$, than $\mathrm{VC}-1$. In separate Thermogravimetric Analysis coupled to Mass Spectrometry 
(TGA-MS) experiments, the reactivity of VC-1 and VC-2 with $\mathrm{CO}_{2}$ at $873 \mathrm{~K}$ was followed for $3 \mathrm{~h}$ (Figure S10). Then, the catalysts were further analyzed by XRD (Figure S11). In both cases, $\mathrm{CO}_{2}$ reacts with $\mathrm{VC}_{\mathrm{x}}$ forming vanadium oxides and releasing $\mathrm{CO}$.

The RWGS reaction was studied over VC-1 and VC-2 samples at $100 \mathrm{kPa}$, and temperatures ranging 573-873 K, using a $\mathrm{CO}_{2} / \mathrm{H}_{2} / \mathrm{N}_{2}=1 / 3 / 1$ (in mols) reactant mixture under a GHSV of $3000 \mathrm{~h}^{-}$ 1. Figure $6 \mathrm{~A}$ shows the $\mathrm{CO}_{2}$ conversion as a function of the reaction temperature, revealing a very low catalytic activity for both catalysts below $673 \mathrm{~K}$. However, the $\mathrm{CO}_{2}$ conversion increases with temperature reaching values of $\sim 33 \%$ and $44 \%$ for $\mathrm{VC}-1$ and $\mathrm{VC}-2$ at $873 \mathrm{~K}$, respectively. Besides $\mathrm{CO}$, only $\mathrm{CH}_{4}$ was formed. Both catalysts display a very high $\mathrm{CO}$ selectivity, increasing with temperature, see Figure 6B, with that of VC-2 being higher than that of VC-1. Consequently, the VC-2 CO yield is always higher than that of VC-1, while both increase with temperature (see Figure S12). The maximum CO yield is gained at $873 \mathrm{~K}$ on VC-2 being about $75 \mathrm{~mol} \mathrm{CO} \mathrm{kg}_{\mathrm{cat}}{ }^{-1} \cdot \mathrm{h}^{-1}$; at $873 \mathrm{~K} \mathrm{CH}_{4}$ selectivity is very low $(<0.05 \%)$. Taking into account that under the reaction conditions used, at temperatures lower than $873 \mathrm{~K}$ the methanation reaction is favored [75], it is noteworthy that even at $673 \mathrm{~K}$ over $\mathrm{VC}-2, \mathrm{a} \mathrm{CH}_{4}$ selectivity of only $0.8 \%$ is found. The different characteristics of $\mathrm{VC}-1$ and $\mathrm{VC}-2$ are also reflected in the apparent activation energy for $\mathrm{CO}$ production, being $0.79 \pm 0.04 \mathrm{eV}$ and $0.55 \pm 0.04 \mathrm{eV}$ for $\mathrm{VC}-1$ and $\mathrm{VC}-2$, respectively, see Figure 7 .

The above observed catalytic behaviour can be understood from the DFT-based calculations. We recall here that two systems are studied; the $\mathrm{VC}(001)$ surface, and the VC-vac derived from $\mathrm{VC}(001)$ with a surface $\mathrm{C}$ vacancy. The $\mathrm{VC}$-vac is used for modeling the $\mathrm{V}_{8} \mathrm{C}_{7}(001)$ phase - see information on the validity of the model in the Experimental section and discussion in section S2 of the Supplementary Material. The adsorption of reactant and intermediate species for both the redox and the associative mechanisms have been acquired, and the PBE-D3 adsorption energies, including the ZPE term, are listed in Table S2 and depicted in Figures S13 and S14 of the Supplementary Material. Here, it is worth highlighting that the presence of $\mathrm{C}$ vacancies on VC makes it much more chemically active, with significant enhanced adsorption strength regardless of the species. Note that the adsorption strengthening is normally directly linked to the vacancy site itself (Figures S13 and S14) with the sole caveat of $\mathrm{H}_{2}$, where the strongest site is the topM site near the vacancy, though. The different chemical activity introduced by the $\mathrm{C}$ vacancy becomes evident from the potential and Gibbs free energy profiles reported in Figure 8. The potential energy $\left(\triangle E^{\neq, Z P E}\right)$ and Gibbs free energy $\left(\Delta G^{\neq}\right)$barriers — see conditions at S2 section in SI - for the different elementary steps are encompassed in Table 1, and the optimized geometries for the transition states are shown in Figures S15 and S16 of the Supplementary Material. 
The potential energy diagram of the RWGS on VC shows low adsorption energies of $\mathrm{CO}_{2}$ and $\mathrm{H}_{2}$, and a moderate $\mathrm{H}_{2}$ dissociation energy barrier of $0.84 \mathrm{eV}$, see Figure 8 . The reaction mechanism can go either through the dissociative $-\mathrm{CO}_{2}$ dissociation- or the associative mechanism $-\mathrm{COOH}$ formation. The common bifurcation point reveals a quite large energy barrier of $1.53 \mathrm{eV}$ for $\mathrm{CO}_{2}$ dissociation in an energy uphill process, and a lower energy barrier of $0.48 \mathrm{eV}$ for the energy downhill $\mathrm{COOH}$ formation. However, the present calculations show that the immediately subsequent reaction step, this is, the $\mathrm{COOH}$ decomposition into $\mathrm{CO}+\mathrm{OH}$, is an uphill process with a high energy barrier of $1.59 \mathrm{eV}$, indicating that the redox mechanism is probably more affordable than the associative mechanism in VC. Indeed, dynamic aspects also would favour $\mathrm{CO}_{2}$ dissociation since it is a unimolecular step, in principle faster than the associative $\mathrm{COOH}$ formation involving a bimolecular step. However, at present, it seems appropriate to consider that both mechanisms would be competitive on $\mathrm{VC}$, although hardly achievable given their high-energy barriers.

The quite unfavourable situation for the RWGS on stoichiometric VC dramatically changes when the surface model involves carbon vacancies at the VC surface in a model mimicking the situation in the VC-2 sample. Here, the energy reaction profile shows significant variations with respect to that of the stoichiometric VC model. In particular, three critical points must be highlighted. First, the reactants adsorb much stronger, with adsorption energies being around three and five times larger for $\mathrm{H}_{2}$ and $\mathrm{CO}_{2}$ than on the stoichiometric surface, respectively (Table S2), and also higher than reported for transition metal catalysts, such as $\mathrm{Ni}(111)$, where the positive $\mathrm{CO}_{2}$ adsorption energy becomes a drawback [76]. Second, the $\mathrm{H}_{2}$ dissociation step is highly enhanced, becoming a highly downhill process, with an energy barrier of solely $0.16 \mathrm{eV}$, thus much reduced compared to the value of $0.65 \mathrm{eV}$ of the VC (001) surface model, see Table 1, and of the order of $\mathrm{H}_{2}$ dissociation on $\mathrm{Ni}(111)$ of $0.1 \mathrm{eV}$ [77]. Finally, the RWGS mechanism gets unbalanced, in the sense that the redox route appears to be much favoured, being sensibly energetically downhill, and with a reduced energy barrier for $\mathrm{CO}_{2}$ dissociation of $0.62 \mathrm{eV}$, which implies an impressive drop of $0.91 \mathrm{eV}$ in such a rate-limiting reaction step, being also smaller than previous estimates of $\mathrm{CO}_{2}$ dissociation on $\mathrm{Ni}(111)$, with computed values of $0.78 \mathrm{eV}$ [76]. Furthermore, the associative mechanism becomes energetically uphill, with a much increased energy barrier, $1.20 \mathrm{eV}$ compared to the $0.48 \mathrm{eV}$ of the vacancy-free $\mathrm{VC}(001)$ surface, even though the following step, this is, the $\mathrm{COOH}$ decomposition into $\mathrm{CO}$ and $\mathrm{OH}$, is here also greatly favoured, with an energy barrier of solely $0.38 \mathrm{eV}$, thus, much reduced compared to the vacancy-free VC case of $1.59 \mathrm{eV}$.

The Gibbs free-energy landscapes (at $\mathrm{T}=873 \mathrm{~K}, p=81.06 \mathrm{kPa}, \mathrm{CO}_{2}: \mathrm{H}_{2}=1: 3$ and assuming $1 \% \mathrm{CO}_{2}$ conversion) mimic the potential energy ones, including the preference for the redox 
mechanism for the model with $\mathrm{C}$ vacancies. The Gibbs free energy barriers are close to the ones corresponding to the potential energy profile, with no systematic deviations, which are, in average, of $\sim 0.09 \mathrm{eV}$. Although $\Delta_{r} G^{o}$ at standard conditions is positive (like $\Delta_{r} E$ ), we have calculated and plotted in Figure 8 the reaction free energy assuming a $1 \% \mathrm{CO}_{2}$ conversion. This is a reasonable value given that in the fixed-bed reactor there is continuous flow of reactants, continuously impinging on the catalyst, where the heterogeneous reaction takes place and afterwards the final gas products leave the catalyst region. The negative value of $\Delta_{r} G^{o}$ indicates that, at these conditions the RWGS is to evolve spontaneously in the forward direction. On a more general overview of the full process, the VC carbide with surface $\mathrm{C}$ vacancies shows a profile with reactants, intermediates, and products close to zero Gibbs free energy, this is, adsorbing reactants, intermediates, and products moderately, and, therefore, being a better catalyst fulfilling Le Sabatier principle. Otherwise, if the material would adsorb reactants, intermediates, and products too weakly, such as in the defect-free $\mathrm{VC}$, the profile is well above the zero energy, and the energetic cost prohibitive, and, on the other hand, if the material would adsorb such chemical moieties too strong, it would become selfpoisoned by such. In summary, the presence of surface $\mathrm{C}$ vacancies largely favours the redox pathway, involving low-energy barriers, plus a moderate stabilization of reaction intermediates; both features explain the excellent capabilities of VC with $\mathrm{C}$ vacancies as a RWGS catalyst, which is fully consistent with the experimental results reported for the VC-2 sample with a larger content of $\mathrm{C}$ vacancies than $\mathrm{VC}-1$. The theoretical calculations also explain the smaller apparent activation energy barrier estimated for the $\mathrm{VC}-2$ sample, given that on $\mathrm{VC}(001)$ the rate-limiting step would feature an energy barrier of $1.41 \mathrm{eV}$, whereas it would drop to $0.48 \mathrm{eV}$ for the $\mathrm{VC}$-vac model, see Table 1. Our experimental and theoretical results suggest that under RWGS conditions the $\mathrm{CO}_{2}$ dissociation takes place forming $\mathrm{CO}$ and $\mathrm{O}$ surface species, the later continuously react with $\mathrm{H}_{2}$ forming $\mathrm{H}_{2} \mathrm{O}$. A similar reaction pathway has been proposed from experimental and theoretical studies for the RWGS over $\alpha-\mathrm{Mo}_{2} \mathrm{C}$ [24].

Last but not least, post-reaction $\mathrm{VC}-1$ and $\mathrm{VC}-2$ catalysts show no relevant structural changes occurred during the catalytic test according to XRD (see Figure S3) plus the $\mathrm{VC}_{\mathrm{x}}$ crystallite size of post-reaction catalysts remains similar to that of the corresponding fresh catalysts. Furthermore, the V $2 p$ and C $1 s$ XPS spectra, see Figures 4B and 5B, respectively, indicate the presence of $\mathrm{V}-\mathrm{C}$ species and an increase in the amount of oxy-vanadium species. The $\mathrm{O} 1 \mathrm{~s}$ spectrum (see Figure S8B) shows that surface oxygen mainly forms oxy-vanadium and $\mathrm{OH}$ and/or oxycarbide species. These results suggest that the redox route dominate over both samples, in good agreement with the theoretical calculations. In order to check the stability of the VC-2 sample, which was the most efficient catalyst, a long-term catalytic test was carried out at $723 \mathrm{~K}$ for 4 days, 
see Figure 9. Initially, during the first $4 \mathrm{~h}, \mathrm{CO}_{2}$ conversion slightly decreased and the $\mathrm{CO}$ selectivity slightly increased. After that, only a slight decrease on $\mathrm{CO}_{2}$ conversion was observed till $30 \mathrm{~h}$ under reaction, meanwhile $\mathrm{CO}$ selectivity remained almost constant at $99.9 \%$. No significant changes in the catalytic behavior of VC-2 were observed during the next $70 \mathrm{~h}$. Clearly, the catalytic activity is marginally affected over reaction time, indirectly suggesting that the surface $C$ vacancies are not remediated in the course of the reaction. The characterization of $\mathrm{VC}-2$ after the long-term catalytic test using XRD (Figure S17) indicated a structural stability of the catalyst, meanwhile the presence of vanadium carbide species on the surface could be determined by XPS spectroscopy (Figure S18).

\section{Conclusions}

New synthetic approaches were used to obtain $\mathrm{VC}_{\mathrm{x}}$ samples with different surface chemistry and catalytic behavior for the RWGS. Based on the results of a series of catalytic experiments, complementary characterization techniques, and DFT calculations, the present work provides compelling evidence that the presence of $\mathrm{C}$ vacancies in vanadium carbide leads to higher activity towards the RWGS reaction with an increased CO selectivity. This is a feature that may be engineered to increase/tune the catalytic activity and selectivity of transition metal carbides, in similar way it has been done for the surface chemistry and catalytic behavior of metal oxides in general [33,34], and for the RWGS catalyzed by supported gold catalysts, in particular [78].

The interpretation of the reported experiments is fully consistent with theoretical results analyzing in detail the molecular mechanism of the RWGS reaction on stoichiometric and C vacancy containing surface models. The calculations confirm that the presence of such vacancies is responsible for the observed catalytic behavior, featuring stronger adsorption energies for reactants - around three and five times larger for $\mathrm{H}_{2}$ and $\mathrm{CO}_{2}$ - and reducing the energy barrier for both $\mathrm{H}_{2}$ and $\mathrm{CO}_{2}$ dissociation steps, by $\sim 0.5$ and $\sim 1 \mathrm{eV}$, respectively, plus the surface vacancy presence appears to be maintained during the reaction process.

To summarize, the present work highlights the importance of carbon vacancy native point defects in the general surface chemistry and catalytic properties of transition metal carbides and paves the way for improving the already high catalytic capability of these interesting materials.

\section{Acknowledgements}

This work was supported by Spanish Ministerio de Economía y Competitividad (MEC) and Ministerio de Ciencia, Innovación y Universidades (MICIUN) through grants MAT2017-87500-P, RTI2018-095460-B-I00 and RTI2018-094757-B-I00, and, in part, by Generalitat de Catalunya 
grants 2017SGR13 and XRQTC. A. P. thanks MINECO for the PhD grant BES-C-2015-074574; F. V. thanks Spanish MEC for the RYC-2012-10129 Ramón y Cajal research contract, and F. I. acknowledges additional support from the 2015 ICREA Academia Award for Excellence in Research. Financial support from Spanish MICIUN through the Excellence María de Maeztu program (grant MDM-2017-0767) is also fully acknowledged. Authors knowledge the scientific and technological centres of University of Barcelona (CCiTUB) for characterization facilities.

\section{Authors contributions}

${ }^{\circledR}$ A. P. and H. P. contributed equally.

\section{Appendix A. Supplementary Material}

The following supplementary information related to this article can be found, in the online version, at DOI

S1. Vanadium carbide synthesis

S2. Validity of our computational model for $\mathrm{V}_{8} \mathrm{C}_{7}$

Figure S1. DFT optimized geometries for $\mathrm{VC}(001)$ with one surface $\mathrm{C}$ vacancy and $\mathrm{V}_{8} \mathrm{C}_{7}(001)$

Figure S2. DFT optimized geometries for $\mathrm{CO}_{2}$ on $\mathrm{VC}(001)$ with one surface $\mathrm{C}$ vacancy and $\mathrm{V}_{8} \mathrm{C}_{7}(001)$

Table S1. DFT adsorption energies for $\mathrm{CO}_{2}$ on $\mathrm{VC}(001)$ with one surface $\mathrm{C}$ vacancy and $\mathrm{V}_{8} \mathrm{C}_{7}(001)$

S3. Free energies

S4. Supplementary Figures

Figure S3. XRD patterns of fresh and post-RWGS catalysts

Figure S4. PED-ASTAR characterization of VC-1

Figure S5. PED-ASTAR characterization of VC-2

Figure S6. Raman spectra of VC-1 and VC-2

Figure S7. $\mathrm{H}_{2}$-TPR profiles of $\mathrm{VC}-1$ and $\mathrm{VC}-2$

Figure S8. XPS profiles of O 1s level of VC-1 and VC-2

Figure S9. XPS profiles of N 1s level of VC-1 and VC-2

Figure $\mathrm{S} 10 . \mathrm{CO}_{2}$ reaction with catalysts followed by TGA-MS

Figure S11. XRD patterns of VC-1 and VC-2 catalysts after $\mathrm{CO}_{2}$ treatment

Figure S12. CO production as a function of T over VC-1 and VC-2 
Figure S13. DFT optimized geometries for $\mathrm{H}, \mathrm{O}, \mathrm{H}_{2}$, and $\mathrm{CO}$ over $\mathrm{VC}(001)$ and $\mathrm{VC}(001)$ containing one surface $\mathrm{C}$ vacancy ( $\mathrm{VC}-\mathrm{vac})$

Figure S14. DFT optimized geometries for $\mathrm{CO}_{2}$ and $\mathrm{COOH}$ over $\mathrm{VC}(001)$ and $\mathrm{VC}(001)$ containing one surface $\mathrm{C}$ vacancy (VC-vac)

Figure S15. TS geometries for $\mathrm{H}-\mathrm{H}$ over $\mathrm{VC}(001)$ and $\mathrm{VC}(001)$ containing one surface $\mathrm{C}$ vacancy (VC-vac)

Figure S16. TS geometries for $\mathrm{CO}{ }^{*} \mathrm{O}, \mathrm{CO}_{2}{ }^{*} \mathrm{H}$, and $\mathrm{CO}{ }^{*} \mathrm{OH}$ over $\mathrm{VC}(001)$ and $\mathrm{VC}(001)$ containing one surface $\mathrm{C}$ vacancy ( $\mathrm{VC}$-vac)

Figure S17. XRD pattern of VC-2 after the RWGS long term catalytic test

Figure S18. XPS profiles of VC-2 catalysts after the RWGS long term catalytic test

S5. Supplementary Tables

Table S2. DFT adsorption energies for $\mathrm{H}, \mathrm{O}, \mathrm{H}_{2}, \mathrm{CO}, \mathrm{CO}_{2}$, and $\mathrm{COOH}$ on $\mathrm{VC}(001)$ and $\mathrm{VC}(001)$ containing one surface $\mathrm{C}$ vacancy (VC-vac)

References 
Figure 1. Top view of the VC (left image) and VC-vac (right image) surface slab models. Black dots show the positions of the tested adsorption sites. $\mathrm{V}$ and $\mathrm{C}$ atoms are shown as light or dark grey spheres, respectively. The $(2 \sqrt{2} \times 2 \sqrt{ } 2) \mathrm{R} 45^{\circ}$ unit cell is shown with dashed lines.

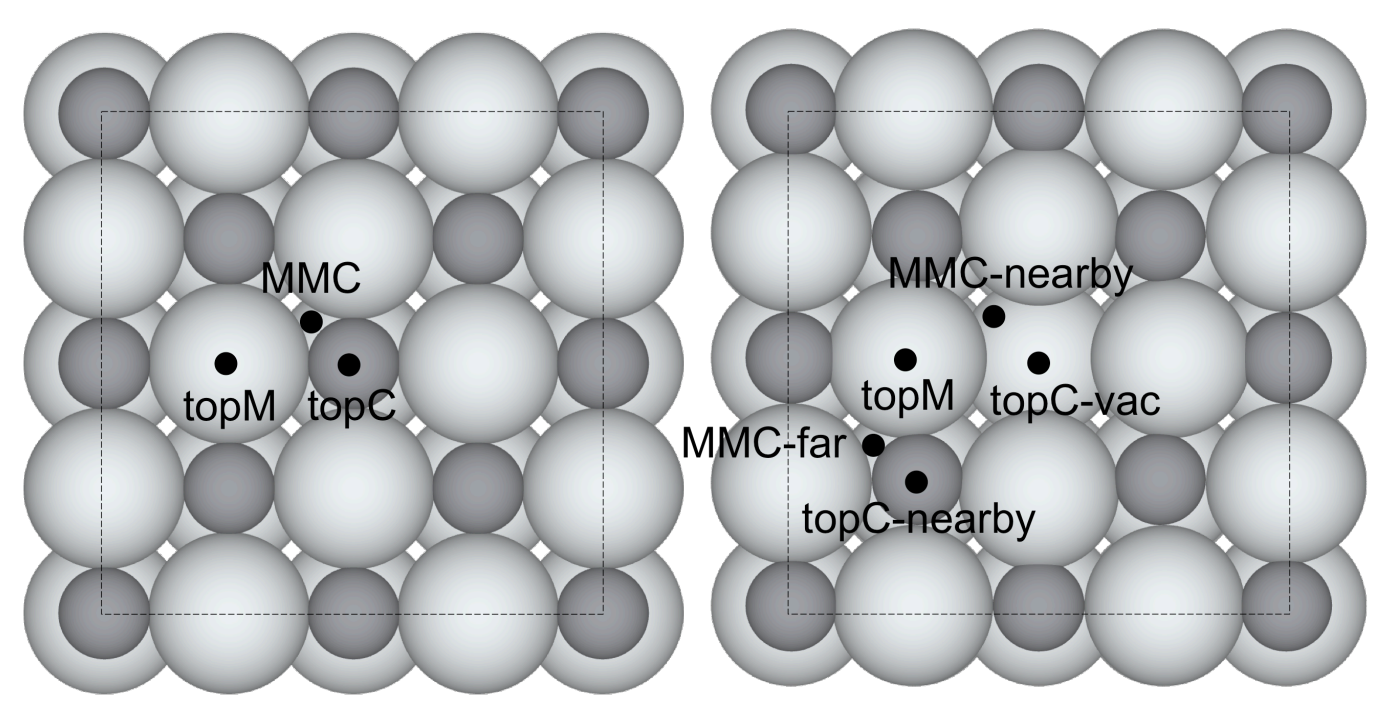


Figure 2. Characterization of VC-1: A) TEM images and particle size distribution; B) STEM image and vanadium EDX mapping combination; C) $\mathrm{VC}_{\mathrm{x}}$ phase mapping determined by PED-ASTAR, see Figure S2 for the electron diffraction pattern and indexation used for phase mapping construction.

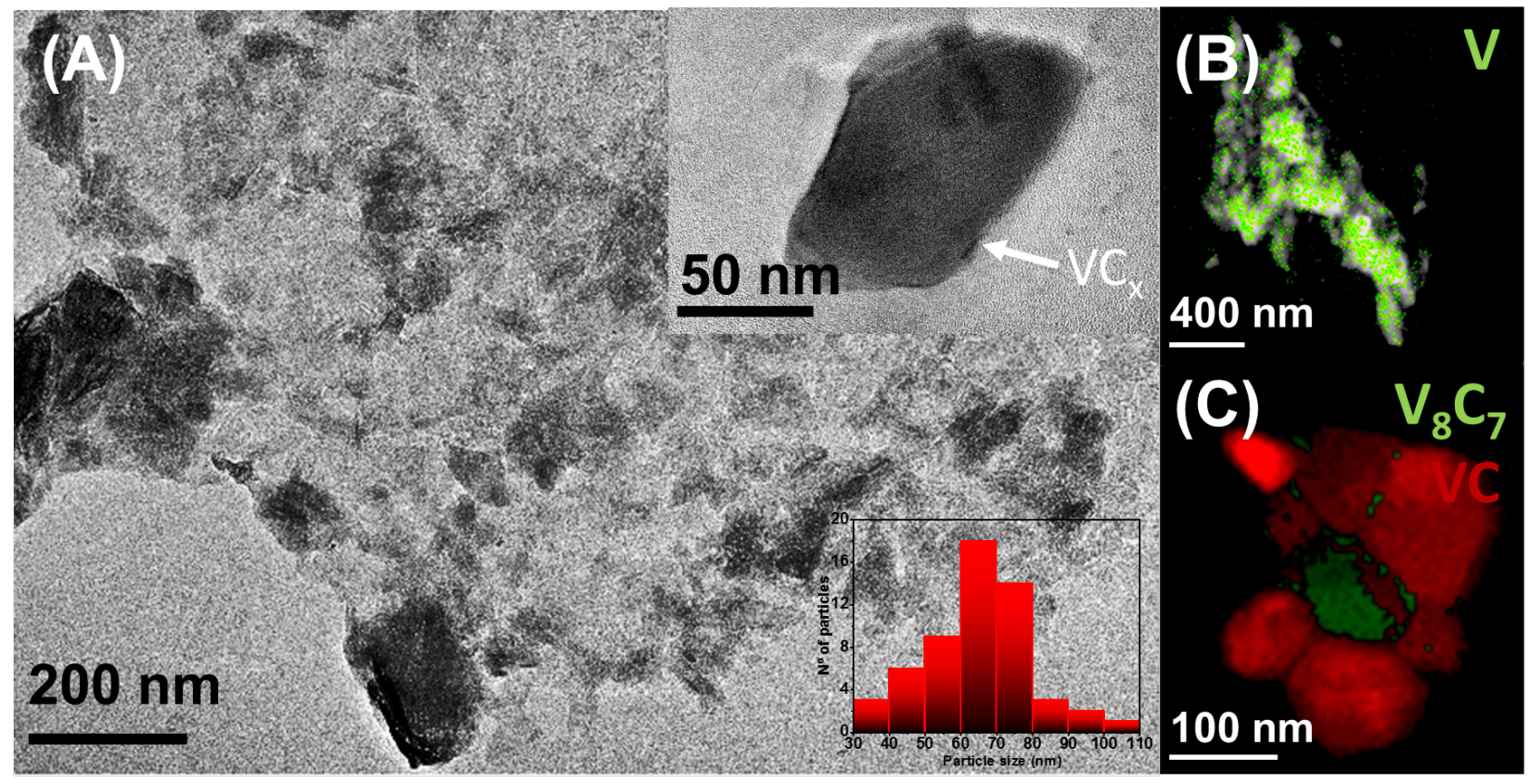


Figure 3. Characterization of VC-2: A) TEM and HRTEM images and particle size distribution; B) STEM image and vanadium EDX mapping combination; C) $\mathrm{VC}_{\mathrm{x}}$ phase mapping determined by PED-ASTAR, see Figure S3 for the electron diffraction pattern and indexation used for phase mapping construction.

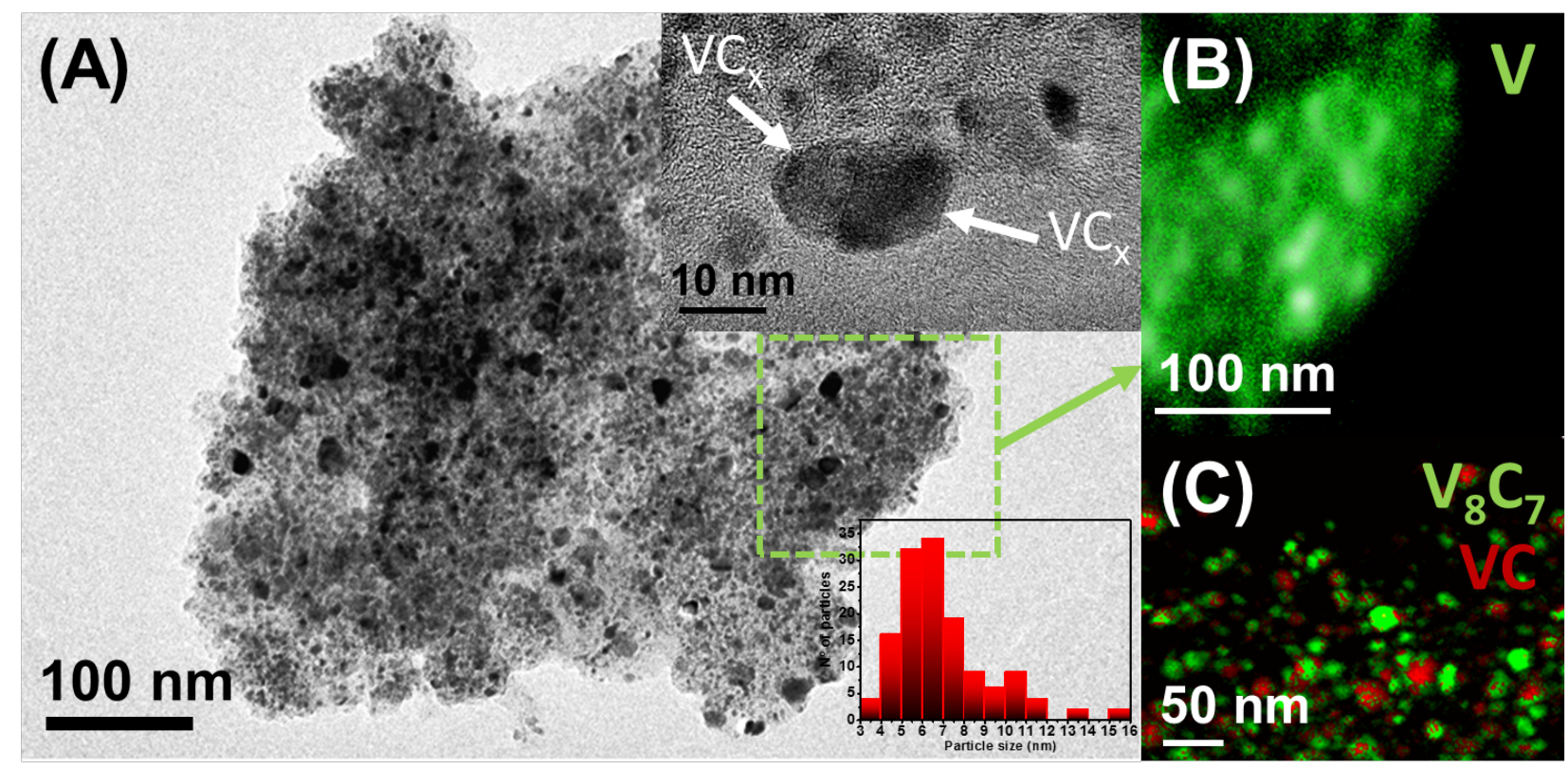


Figure 4. XPS profiles of V $2 p$ levels of catalysts: A) fresh catalysts; B) after the RWGS catalytic tests.
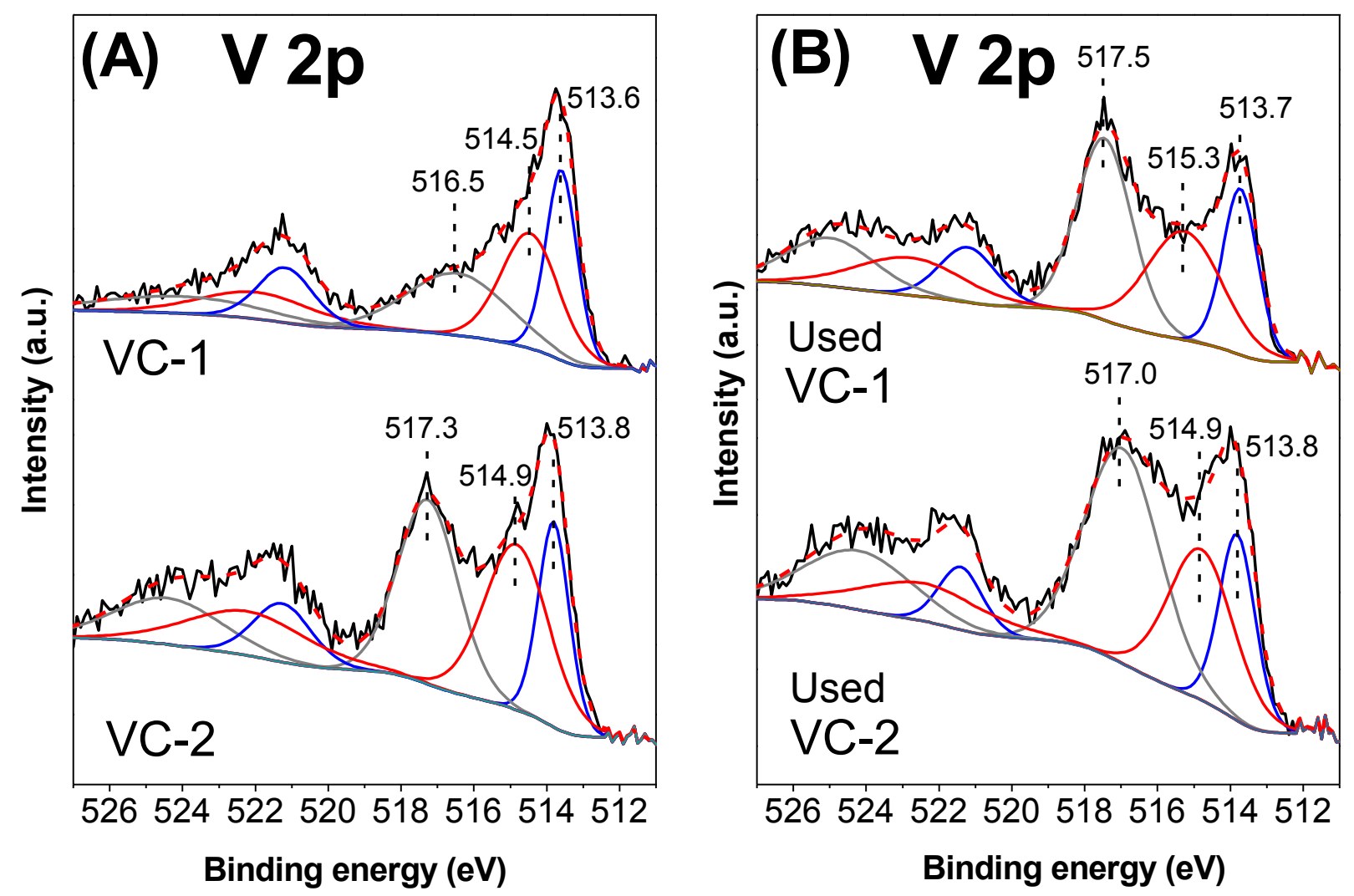
Figure 5. XPS profiles of C $1 s$ level of catalysts: A) fresh catalysts; B) after the RWGS catalytic tests.
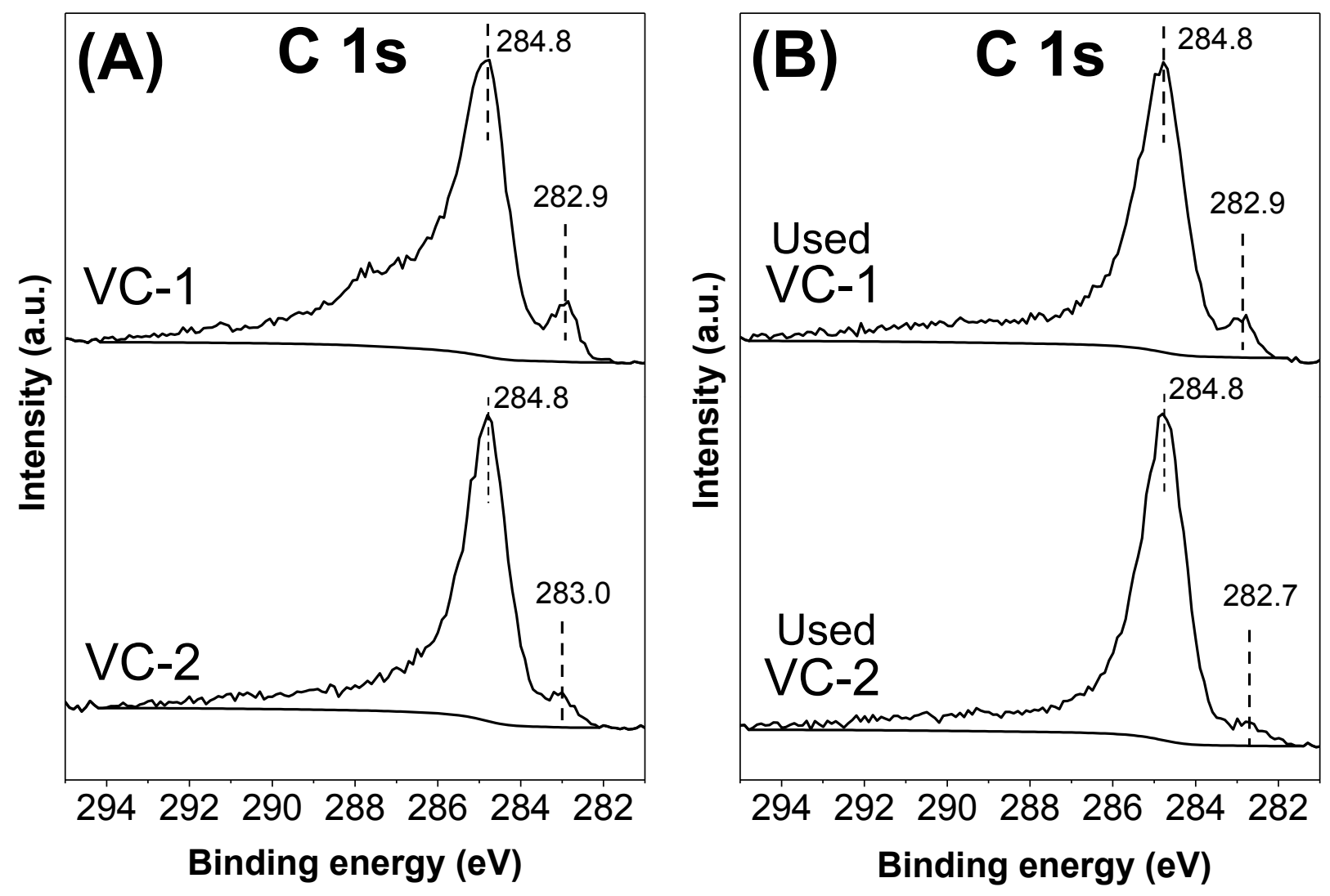
Figure 6. Catalytic behavior of $\mathrm{VC}-1$ and $\mathrm{VC}-2$ in the RWGS reaction as a function of reaction temperature: A) $\mathrm{CO}_{2}$ conversion; B) $\mathrm{CO}$ selectivity, gray bars: $\mathrm{VC}-1$ and green bars: VC-2. Reaction conditions: $\mathrm{m}_{\text {cat }}=150 \mathrm{mg}, \mathrm{CO}_{2} / \mathrm{H}_{2} / \mathrm{N}_{2}=1 / 3 / 1$, GHSV $=3000 \mathrm{~h}^{-1}, \mathrm{P}=0.1 \mathrm{MPa}$.
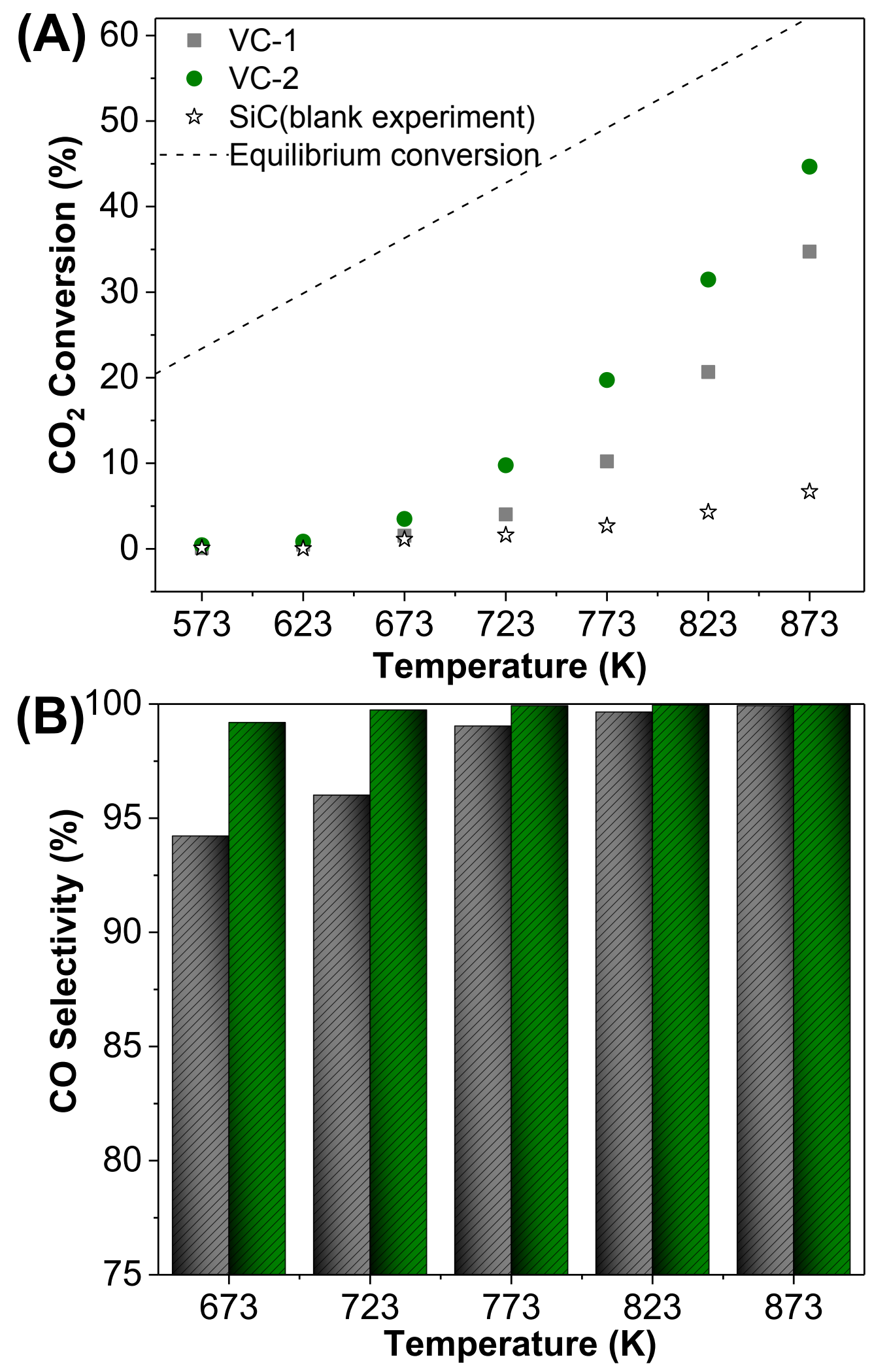
Figure 7. Apparent activation energy $\left(\mathrm{E}_{\mathrm{a}}\right)$ for $\mathrm{CO}$ production over VC-1 and VC-2. Reaction conditions: $\mathrm{m}_{\text {cat }}=150 \mathrm{mg}, \mathrm{CO}_{2} / \mathrm{H}_{2} / \mathrm{N}_{2}=1 / 3 / 1$, GHSV $=3000 \mathrm{~h}^{-1}, p=0.1 \mathrm{MPa}, \mathrm{T}=723-873 \mathrm{~K}$. The activation barriers found are $53.4 \pm 3.8 \mathrm{~kJ}$ mol- $1(0.55 \pm 0.04 \mathrm{eV})$ for $\mathrm{VC}-1$, and $76.5 \pm 4.0(0.79 \pm 0.04$ $\mathrm{eV})$ for $\mathrm{VC}-2$.

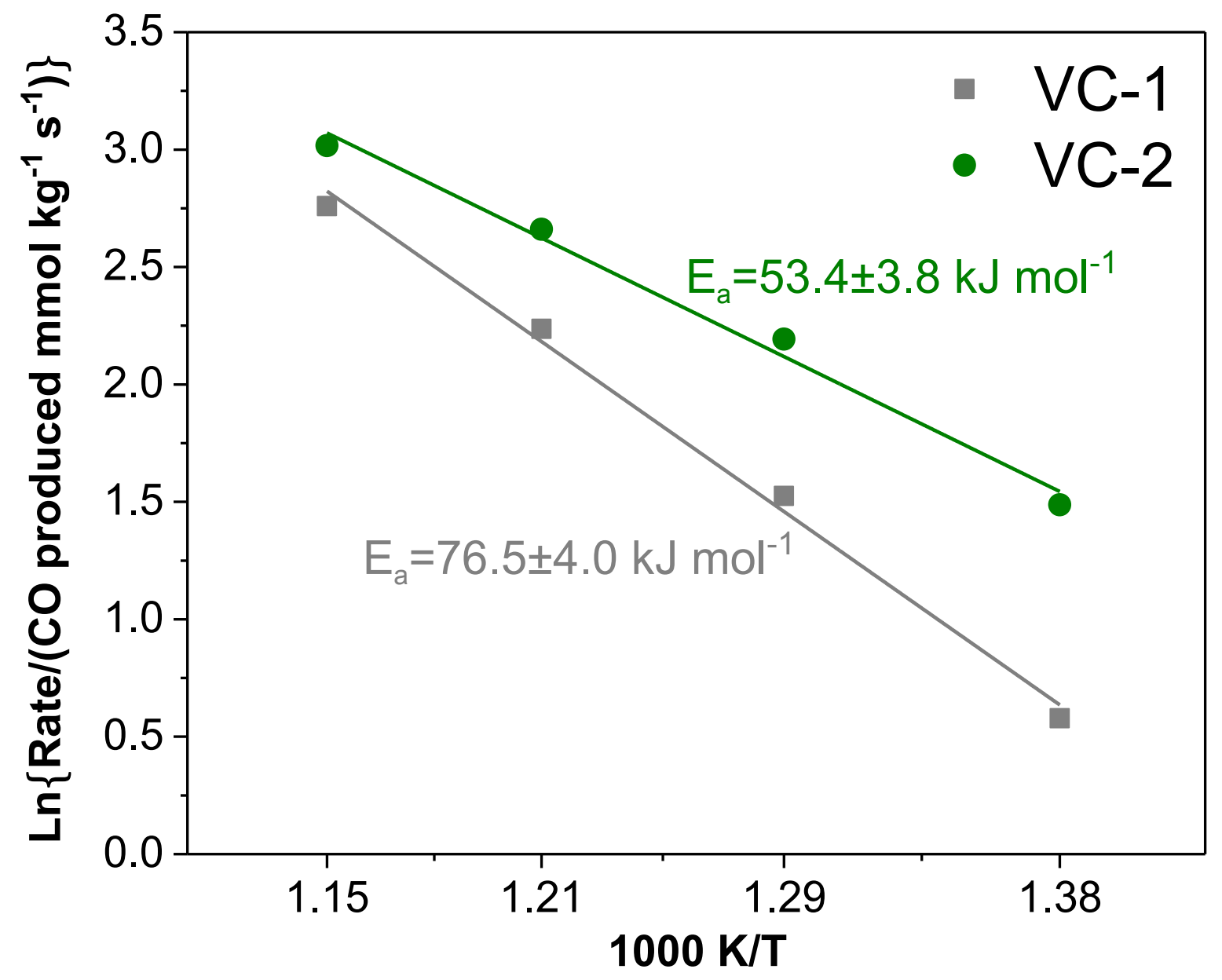


Figure 8. Upper panel: Potential energy reaction profiles (PBE-D3 including the ZPE term) for the RWGS on the VC (001) surface (grey) and on the VC-vac (001) surface model (green). Lower panel: Equivalent Gibbs free energy reaction profiles at $T=873 \mathrm{~K}, p_{\mathrm{CO}_{2}}=20.26 \mathrm{kPa}, p_{\mathrm{H}_{2}}=60.79$ $\mathrm{kPa}$, and $p_{\mathrm{CO}}=p_{\mathrm{H}_{2} \mathrm{O}}=0.20 \mathrm{kPa}$.
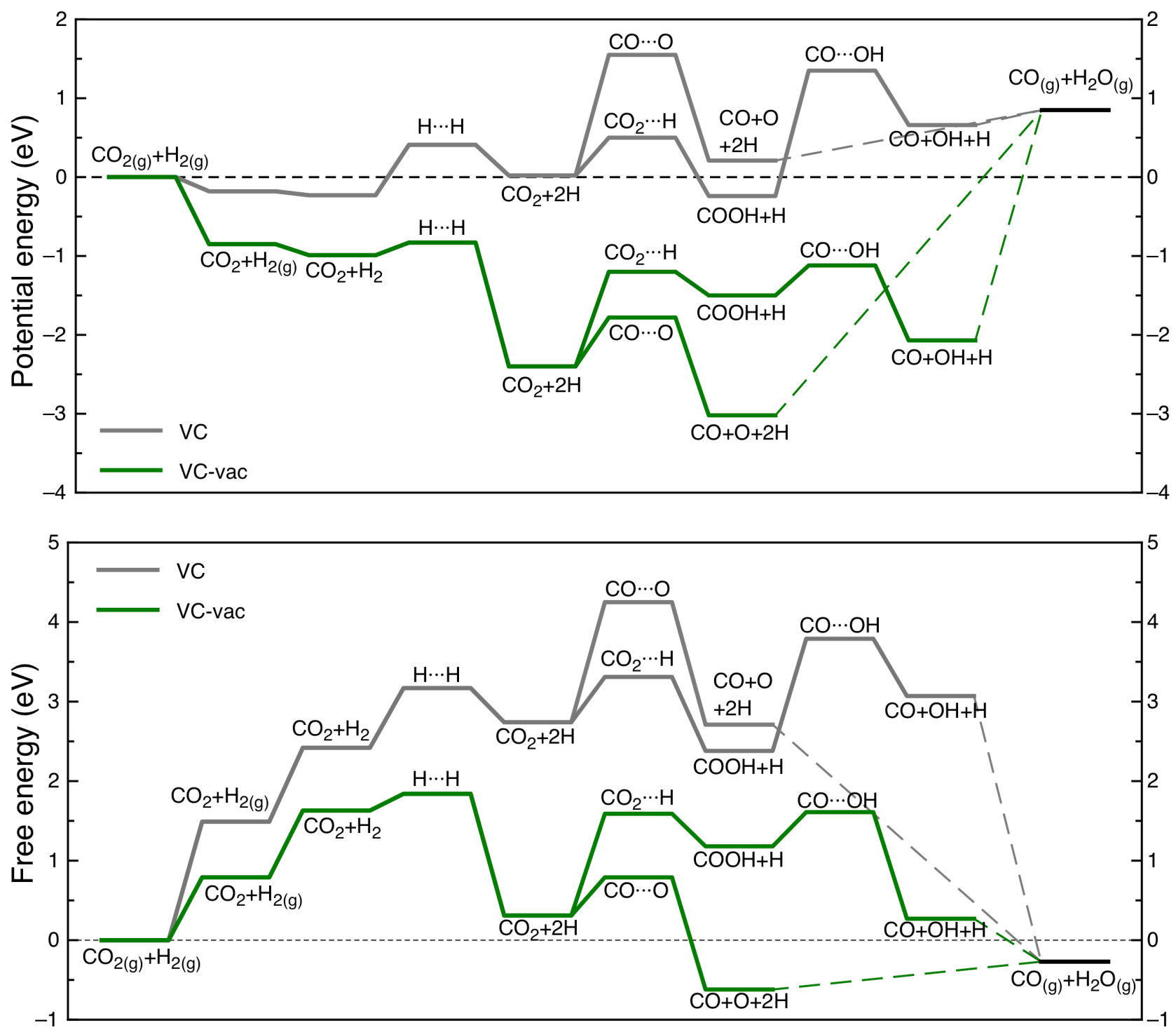
Figure 9. Catalytic behavior of VC-2 in RWGS at $723 \mathrm{~K}$ as a function of time on stream: $\mathrm{CO}_{2}$ conversion and $\mathrm{CO}$ selectivity. Reaction conditions: $\mathrm{m}_{\text {cat }}=300 \mathrm{mg}, \mathrm{CO}_{2} / \mathrm{H}_{2} / \mathrm{N}_{2}=1 / 3 / 1, \mathrm{GHSV}=$ $3000 \mathrm{~h}^{-1}, p=0.1 \mathrm{MPa}$.

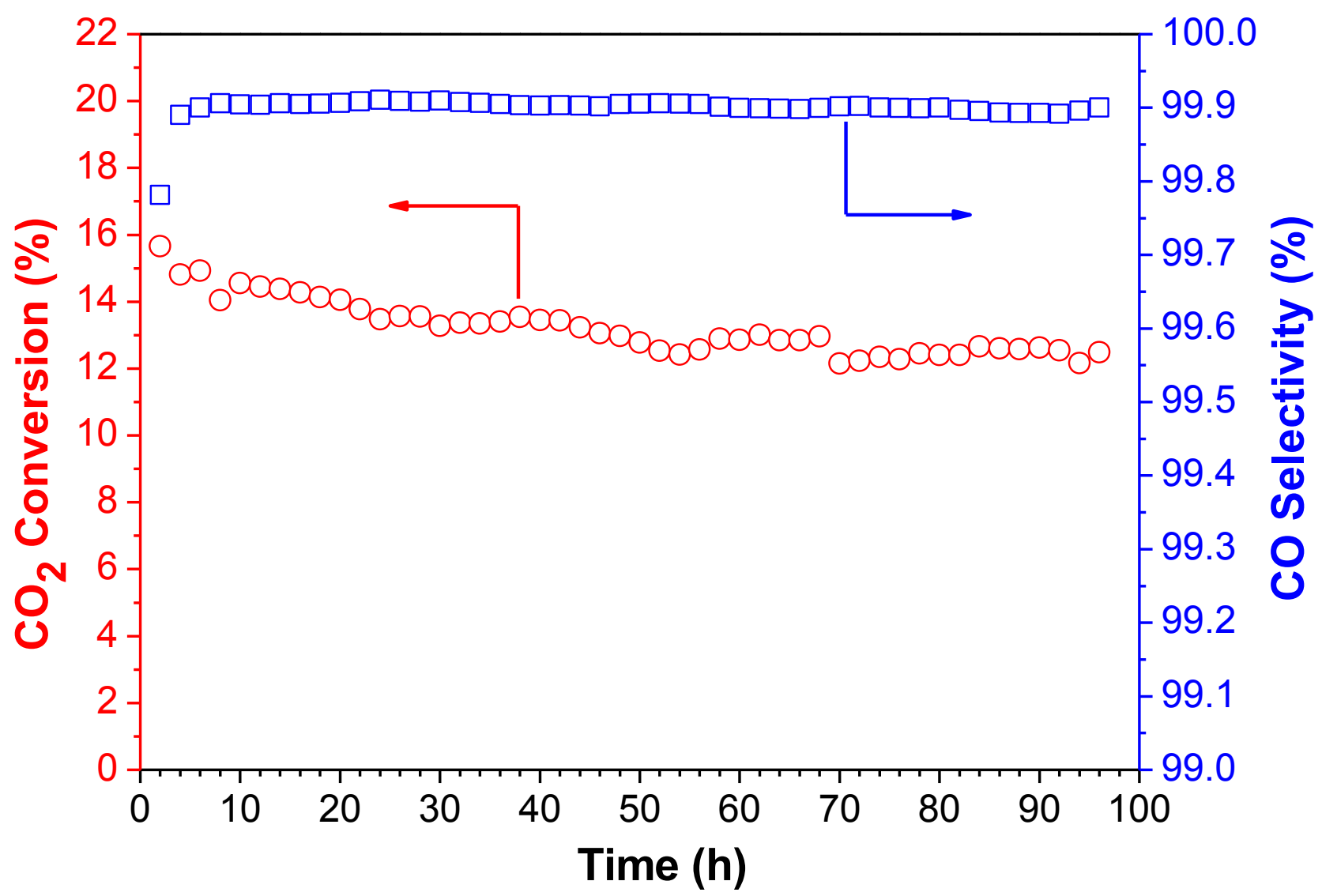


Table 1. Potential $\left(\triangle E^{\neq, Z P E}\right)$ and free energy $\left(\Delta G^{\neq}\right)$barriers for different elementary steps of the RWGS on the (001) surface models of VC, and of the same surface containing a surface $\mathrm{C}$ vacancy (VC-vac). All values are ZPE-corrected and have been obtained at the PBE-D3 level. The Gibbs free energy values are gained at $T=873 \mathrm{~K}, p_{\mathrm{CO}_{2}}=20.26 \mathrm{kPa}, p_{\mathrm{H}_{2}}=60.79 \mathrm{kPa}$, and $p_{C O}=p_{\mathrm{H}_{2} \mathrm{O}}=$ $0.20 \mathrm{kPa}$.

\begin{tabular}{ccccc}
\hline & $\Delta E^{\neq, Z P E} / \mathrm{eV}$ & \multicolumn{3}{c}{$\Delta G^{\neq} / \mathrm{eV}$} \\
Reaction Step & $\mathrm{VC}$ & $\mathrm{VC}-\mathrm{vac}$ & $\mathrm{VC}$ & $\mathrm{VC}-\mathrm{vac}$ \\
\hline \hline $\mathrm{H}_{2} \rightarrow 2 \mathrm{H}$ & 0.65 & 0.16 & 0.74 & 0.21 \\
$\mathrm{CO}_{2} \rightarrow \mathrm{CO}+\mathrm{O}$ & 1.53 & 0.62 & 1.51 & 0.48 \\
$\mathrm{CO}_{2}+\mathrm{H} \rightarrow \mathrm{COOH}$ & 0.48 & 1.20 & 0.57 & 1.29 \\
$\mathrm{COOH} \rightarrow \mathrm{CO}+\mathrm{OH}$ & 1.59 & 0.38 & 1.41 & 0.43 \\
\hline
\end{tabular}




\section{References}

[1] W. Taifan, J.-F. Boily, J. Baltrusaitis, Surface chemistry of carbon dioxide revisited. Surf. Sci. Rep. 71 (2016) 595-671.

[2] D.Y.C. Leung, G. Caramanna, M.M. Maroto-Valer, An overview of current status of carbon dioxide capture and storage technologies. Renew. Sustain. Energy Rev. 39 (2014) 426-443.

[3] D.M. D’Alessandro, B. Smit, J.R. Long, Carbon dioxide capture: Prospects for new materials. Angew. Chem. Int. Ed. 49 (2010) 6058-6082.

[4] M.E. Boot-Handford, J.C. Abanades, E.J. Anthony, M.J. Blunt, S. Brandani, N. Mac Dowell, J.R. Fernández, M.-C. Ferrari, R. Gross, J.P. Hallett, R.S. Haszeldine, P. Heptonstall, A. Lyngfelt, Z. Makuch, E. Mangano, R.T.J. Porter M. Pourkashanian, G.T. Rochelle, N. Shah, J.G. Yao, P. S. Fennell, Carbon capture and storage update. Energy Environ. Sci. 7 (2014) 130-189.

[5] P. Markewitz, W. Kuckshinrichs, W. Leitner, J. Linssen, P. Zapp, R. Bongartz, A. Schreiber, T.E. Müller, Worldwide innovations in the development of carbon capture technologies and the utilization of $\mathrm{CO}_{2}$. Energy Environ. Sci. 5 (2012) 7281-7305.

[6] M.W. Chase Jr., NIST-JANAF Thermochemical Tables. $4^{\text {th }}$ Edition, J. Phys. Chem. Ref. Data, Monograph 9, 1-1951, 1998.

[7] C. Graves, S.D. Ebbesen, M. Mogesen, K.S. Lackner, Sustainable hydrocarbon fuels by recycling $\mathrm{CO}_{2}$ and $\mathrm{H}_{2} \mathrm{O}$ with renewable or nuclear energy. Renew. Sustain. Energy Rev. 15 (2011) $1-23$.

[8] W. Wang, S. Wang, X. Ma, J. Gong, J. Recent advances in catalytic hydrogenation of carbon dioxide. Chem. Soc. Rev. 40 (2011) 3703-3727.

[9] C. Kunkel, F. Viñes, F. Illas, Transition metal carbides as novel materials for $\mathrm{CO}_{2}$ capture, storage, and activation. Energy Environ. Sci. 9 (2016) 141-144.

[10] R.B. Levy, M. Boudart, Platinum-like behavior of tungsten carbide in surface catalysis. Science 181 (1973) 547-549.

[11] H.H. Hwu, J.G. Chen, Surface chemistry of transition metal carbides. Chem. Rev. 105 (2005) $185-212$.

[12] J.A. Rodriguez, P. Liu, J. Dvorak, T. Jirsak, J. Gomes, Y. Takahashi, K. Nakamura, Adsorption of sulfur on TiC(001): Photoemission and first-principles studies. Phys. Rev. B 69 (2004) 115414.

[13] A.R.S. Darujati, D.C. LaMont, W.J. Thomson, Oxidation stability of $\mathrm{Mo}_{2} \mathrm{C}$ catalysts under fuel reforming conditions. J. Appl. Catal. A 253 (2003) 397-407.

[14] P. Liu, J.A. Rodriguez, J.T. Muckerman, Sulfur adsorption and sulfidation of transition metal carbides as hydrotreating catalysts. J. Mol. Catal. A 239 (2005) 116-124. 
[15] D.J. Sajkowski, S.T. Oyama, Catalytic hydrotreating by molybdenum carbide and nitride: unsupported $\mathrm{Mo}_{2} \mathrm{~N}$ and $\mathrm{Mo}_{2} \mathrm{C} / \mathrm{Al}_{2} \mathrm{O}_{3}$. Appl. Catal. A 134 (1996) 339-349.

[16] C. Kunkel, F. Viñes, F. Illas, Biogas upgrading by transition metal carbides. ACS Appl. Energy Mater. 1 (2018) 43-47.

[17] T. Takahashi, S. Sutherland, A. Kozyr, Global ocean surface water partial pressure of $\mathrm{CO}_{2}$ database: Measurements performed during 1957-2017, Environmental Sciences Division, Oak Ridge National Laboratory, 2018.

[18] C. Kunkel, F. Viñes, P.J. Ramírez, J.A. Rodriguez, F. Illas, Combining theory and experiment for multitechnique characterization of activated $\mathrm{CO}_{2}$ on transition metal carbide (001) surfaces. J. Phys. Chem. C 123 (2019) 7567-7576.

[19] J.J. Piñero, P.J. Ramírez, S.T. Bromley, F. Viñes, F. Illas, J.A. Rodriguez, Diversity of adsorbed hydrogen on the TiC (001) surface at high coverages. J. Phys. Chem. C 122 (2018), 28013-28020.

[20] S. Posada-Pérez, F. Viñes, R. Valero, J.A. Rodriguez, F. Illas, Adsorption and dissociation of molecular hydrogen on orthorhombic $\beta-\mathrm{Mo}_{2} \mathrm{C}$ and $\mathrm{Cubic} \delta$-MoC (001) surfaces. Surf. Sci. 656 (2017) 24-32.

[21] H. Prats, J.J. Piñero, F. Viñes, S.T. Bromley, R. Sayós and F. Illas, Assessing the usefulness of transition metal carbides for hydrogenation reactions. Chem. Comm. 55 (2019) 12797-12800.

[22] S. Posada-Pérez, F. Viñes, J.A. Rodriguez, F. Illas, Fundamentals of methanol synthesis on metal carbide based catalysts: Activation of $\mathrm{CO}_{2}$ and $\mathrm{H}_{2}$. Top. Catal. 58 (2015) 159-173.

[23] A. Goguet, F. Meunier, J.P. Breen, R. Burch, M.I. Petch, A. Faur Ghenciu, Study of the origin of the deactivation of a Pt/CeO $\mathrm{Ce}_{2}$ catalyst during Reverse Water Gas Shift (RWGS) reaction. J. Catal. 226 (2004) 382-392.

[24] X. Liu, C. Kunkel, P. Ramírez de la Piscina, N. Homs, F. Viñes, F. Illas, Effective and highly selective $\mathrm{CO}$ generation from $\mathrm{CO}_{2}$ using a polycrystalline $\alpha-\mathrm{Mo}_{2} \mathrm{C}$ catalyst. ACS Catal. 7 (2017) 4323-4335.

[25] M.D. Porosoff, S. Kattel, W. Li, P. Liu, J.G. Chen, Identifying trends and descriptors for selective $\mathrm{CO}_{2}$ conversion to $\mathrm{CO}$ over transition metal carbides. Chem. Commun. 51 (2015) 6988-6991.

[26] M. D. Porosoff, X. Yang, J.A. Boscoboinik, J.G. Chen, Molybdenum carbide as alternative catalysts to precious metals for highly selective reduction of $\mathrm{CO}_{2}$ to $\mathrm{CO}$. Angew. Chem. 126 (2014) 6823-6827. 
[27] S. Posada-Pérez, F. Viñes, P.J. Ramírez, A.B. Vidal, J.A. Rodriguez, F. Illas, The bending machine: $\mathrm{CO}_{2}$ activation and hydrogenation on $\delta-\mathrm{MoC}(001)$ and $\beta-\mathrm{Mo}_{2} \mathrm{C}(001)$ surfaces. Phys. Chem. Chem. Phys. 16 (2014) 14912-14921.

[28] S. Posada-Pérez, P.J. Ramirez, J. Evans, F. Viñes, P. Liu, F. Illas, J.A. Rodriguez, Highly active $\mathrm{Au} / \delta-\mathrm{MoC}$ and $\mathrm{Cu} / \delta-\mathrm{MoC}$ catalysts for the conversion of $\mathrm{CO}_{2}$ : The metal/C Ratio as a key factor defining activity, selectivity, and stability. J. Am. Chem. Soc. 138 (2016) 8269-8278.

[29] S. Posada-Pérez, R.A. Gutierrez, Z.J. Zuo, P.J. Ramirez, F. Viñes, P. Liu, F. Illas, J. Rodriguez, Highly active $\mathrm{Au} / \mathrm{\delta}-\mathrm{MoC}$ and $\mathrm{Au} / \beta-\mathrm{Mo}_{2} \mathrm{C}$ catalysts for the low-temperature water gas shift reaction: Effects of the carbide metal/carbon ratio on the catalyst performance. Catal. Sci. Technol. 7 (2017) $5332-5342$.

[30] H. Fang, A. Roldan, C. Tian, Y. Zheng, X. Duan, K. Chen, L. Ye, S. Leoni, Y. Yuan, Structural and catalysis of tungsten carbides for the regioselective cleavage of C-O bonds, J. Catal. 369 (2019) 283-295.

[31] Y. Zhang, B. Liu, J. Wang, Self-assembly of carbon vacancies in sub-stoichiometric $\mathrm{ZrC}_{1-\mathrm{x}}$. Sci. Rep. 5 (2015) 18098.

[32] H.W. Hugosson, P. Korzhavyi, U. Jansson, B. Johansson, O. Eriksson, Phase stabilities and

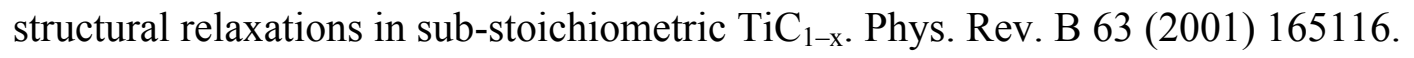

[33] G. Pacchioni, Oxygen vacancy: The invisible agent on oxide surfaces. ChemPhysChem 4 (2003) 1041-1047.

[34] C.T. Campbell, C.H.F. Peden, Oxygen vacancies and catalysis on ceria surfaces. Science 309 (2005) 713-714 and references therein.

[35] S.J. Tauster, S.C. Fung, R.L. Garten, Strong metal-support interactions - Group-8 noble-metals supported on $\mathrm{TiO}_{2}$. J. Am. Chem. Soc. 100 (1978) 170-175.

[36] S.J. Tauster, S.C. Fung, R.T.K. Baker, J.A. Horsley, Strong-interactions in supported-metal catalysts. Science 211 (1981) 1121-1125.

[37] W. Dong, Q. Fu, Z. Jiang, B. Mei, X. Bao, Carbide-supported Au catalysts for water-gas shift reactions: A new territory for the strong metal-support interaction Effect. J. Am. Chem. Soc. 140 (2018) 13808-13816.

[38] J.R. Kitchin, J.K. Nørskov, M.A. Barteau, J.G. Chen, Trends in the chemical properties of early transition metal carbide surfaces: A density functional study. Catal. Today 105 (2005) 66-73. [39] Y.F. Zhang, F. Viñes, Y.J. Xu, Y. Li, J.Q. Li, F. Illas, Role of kinetics in the selective surface oxidations of transition metal carbides. J. Phys. Chem. B 110 (2006) 15454-15458. 
[40] F. Viñes, C. Sousa, F. Illas, P. Liu, J.A. Rodriguez, Density functional study of the adsorption of atomic oxygen on the (001) surface of early transition-metal carbides. J. Phys. Chem. C 111 (2007) 1307-1314.

[41] F. Viñes, C. Sousa, F. Illas, P. Liu, J.A. Rodriguez, A systematic density functional study of molecular oxygen adsorption and dissociation on the (001) surface of group IV-VI transition metal carbides. J. Phys. Chem. C 111 (2007) 16982-16989.

[42] X. Peng, L. Hu, L. Wang, X. Zhang, J. Fu, K. Huo, L.Y.S. Lee, K.-Y. Wong, P.K. Chu, Vanadium carbide nanoparticles encapsulated in graphitic carbon network nanosheets: A highefficiency electrostatic for hydrogen evolution reaction. Nano Energy 26 (2016) 603-609.

[43] C. Giordano, C. Erpen, W. Yao, B. Milke, M. Antonietti, Metal nitride and metal carbide nanoparticles by a soft urea pathway. Chem. Mater. 21 (2009) 5136-5144.

[44] X. Liu, A. Pajares, D.J.D. Calinao Matienzo, P. Ramírez de la Piscina, N. Homs, Preparation and characterization of bulk $\mathrm{Mo}_{\mathrm{x}} \mathrm{C}$ catalysts and their use in the reverse water-gas shift reaction. Catal. Today, DOI: 10.1016/j.cattod.2019.11.011.

[45] M. Nagai, K. Oshikawa, T. Kurakami, T. Miyao, S. Omi, Surface properties of carbided molybdena-alumina and its activity for $\mathrm{CO}_{2}$ hydrogenation. J. Catal. 180 (1998) 14-23.

[46] W. Wu, Z. Wu, C. Liang, X. Chen, P. Ying, C. Li, In Situ FT-IR Spectroscopic studies of CO adsorption on fresh $\mathrm{Mo}_{2} \mathrm{C} / \mathrm{Al}_{2} \mathrm{O}_{3}$ Catalyst. J. Phys. Chem. B 107 (2003) 7088-7094.

[47] W. Wu, Z. Wu, C. Liang, P. Ying, Z. Feng, C. Li, An IR study on the surface passivation of $\mathrm{Mo}_{2} \mathrm{C} / \mathrm{Al}_{2} \mathrm{O}_{3}$ catalyst with $\mathrm{O}_{2}, \mathrm{H}_{2} \mathrm{O}$ and $\mathrm{CO}_{2}$. Phys. Chem. Chem. Phys. 6 (2004) 5603-5608.

[48] D. Viladot, M. Véron, M. Gemmi, F. Peiró, J. Portillo, S. Estradé, J. Mendoza, N. Llorca-Isern, S. Nicolopoulos, Orientation and phase mapping in the transition electron microscope using precession-assisted diffraction spot recognition: State-of-the-art results. J. Microsc. 252 (2013) 2334.

[49] E.F. Rauch, M. Véron, Automated crystal orientation and phase mapping in TEM. Mater. Charact. 98 (2014) 1-9.

[50] S. Rouvimov, E.F. Rauch, P. Moeck, S. Nicolopoulos, Automated crystal orientation and phase mapping of iron oxide nano-crystals in a transmission electron microscope. Microsc. Microanal. 15 (2009) 1290-1291.

[51] G. Kresse, J. Furthmüller, Efficient iterative schemes for ab initio total-energy calculations using a plane-wave basis set. Phys. Rev. B 54 (1996) 11169-11186.

[52] J.P. Perdew, K. Burke, M. Ernzerhof, Generalized gradient approximation made simple. Phys. Rev. Lett. 77 (1996) 3865-3868. 
[53] S. Grimme, J. Antony, S. Ehrlich, H. Krieg, A consistent and accurate ab initio parametrization of density functional dispersion correction (DFT-D) for the 94 elements H-Pu. J. Chem. Phys 132 (2010) 154104.

[54] P.E. Blöchl, Projector augmented-wave method. Phys. Rev. B 50 (1994) 17953-17979.

[55] G. Kresse, D. Joubert, From ultrasoft pseudopotentials to the projector augmented-wave method. Phys. Rev. B 59 (1999) 1758-1775.

[56] H.J. Monkhorst, J.D. Pack, Special points for Brillouin-zone integrations. Phys. Rev. B 13 (1976) 5188-5192.

[57] M.G. Quesne, A. Roldan, N.H. Leeuw, C.R.A. Catlow, Bulk and surface properties of metal carbides: Implications for catalysis. Phys. Chem. Chem. Phys. 20 (2018) 6905-6916.

[58] F. Viñes, J.R.B. Gomes, F. Illas, Understanding the reactivity of metallic nanoparticles: beyond the extended surface model for catalysis. Chem. Soc. Rev. 43 (2014) 4922-4939.

[59] G. Henkelman, B.P. Uberuaga, H. Jónsson, A climbing image nudged elastic band method for finding saddle points and minimum energy paths. J. Chem. Phys. 113 (2000) 9901-9904.

[60] A. Hjorth Larsen, J. Jørgen Mortensen, J. Blomqvist, I.E. Castelli, R. Christensen, M. Dułak, J. Friis, M.N. Groves, B. Hammer, C. Hargus, E.D. Hermes, P.C. Jennings, P.B. Jensen, J. Kermode, J.R. Kitchin, E.L. Kolsbjerg, J. Kubal, K. Kaasbjerg, S. Lysgaard, J.B. Maronsson, T. Maxson, T. Olsen, L. Pastewka, A. Peterson, C. Rostgaard, J. Schiøtz, O. Schütt, M. Strange, K.S. Thygesen, Vegge, L. Vilhelmsen, M. Walter, Z. Zeng, K.W. Jacobsenet, The atomic simulation environment A Python library for working with atoms. J. Phys. Condens. Matter 29 (2017) 273002.

[61] S. Smidstrup, A. Pedersen, K. Stokbro, H. Jónsson, Improved initial guess for minimum energy path calculations. J. Chem. Phys. 140 (2014) 214106.

[62] J. Rogal, K. Reuter, Ab initio atomistic thermodynamics for surfaces: A primer in experiment, modeling and simulation of gas-surface interactions for reactive flows in hypersonic flights. Educational notes. Neuilly-sur- Seine, France (2007).

[63] F. Roozeboom, M.C. Mittelmeijer, J.A. Moulijn, J. Medema, V.H.J. De Beer, P.J. Gellings, Vanadium oxide monolayer catalysts. 3. A Raman spectroscopic and temperature-programmed reduction study of monolayer and crystal-type vanadia on various supports, J. Phys. Chem. 84 (1980) 2783-2791.

[64] G. Liu, Z.-J. Zhao, T. Wu, L. Zeng, J. Gong, Nature of the active sites of $\mathrm{VO}_{\mathrm{x}} / \mathrm{Al}_{2} \mathrm{O}_{3}$ catalysts for propane dehydrogenation. ACS Catal. 6 (2016) 5207-5214. 
[65] D.A. Bulushev, L. Kiwi-Minsker, F. Rainone, A. Renken, Characterization of surface vanadia forms on V/Ti-Oxide catalyst via temperature-programmed reduction in hydrogen and spectroscopic methods, J. Catal. 205 (2002) 115-122.

[66] F. Arena, F. Frusteri, A. Parmaliana, Structure and dispersion of supported-vanadia catalysts. Influence of the oxide carrier, Appl. Catal. A. 176 (1999) 189-199.

[67] J.-G. Choi, The surface properties of vanadium compounds by X-Ray photoelectron spectroscopy, Appl. Surf. Sci. 148 (1999) 64-72.

[68] M.C. Biesinger, L.W.M. Lau, A.R. Gerson, R.St.C. Smart, Resolving surface chemical states in XPS analysis of first row transition metals, oxides and hydroxides: Sc, Ti, V, Cu and Zn. Appl. Surf. Sci. 257 (2010) 887-898.

[69] G. Silversmit, D. Depla, H. Poelman, G.B. Marin, R.D. Gryse, Determination of the V2p XPS binding energies for different vanadium oxidation states $\left(\mathrm{V}^{5+}\right.$ to $\left.\mathrm{V}^{0+}\right)$. J. Electron. Spectros. Relat. Phenomena 135 (2004) 167-175.

[70] S. Kaur, G. Cherkashinin, C. Fasel, H.J. Kleebe, E. Ionescu, R.J. Riedel, Single-sourceprecursor synthesis of novel $\mathrm{V}_{8} \mathrm{C}_{7} / \mathrm{SiC}(\mathrm{O})$-based ceramic nanocomposites. J. Eur. Ceram. 36 (2016) 3553-3563.

[71] D. Yang, A. Velamakanni, G. Bozoklu, S. Park, M. Stoller, R.D. Piner, S. Stankovich, I. Jung, D.A. Field, C.A. Ventrice Jr., R.S. Ruoff, Chemical analysis of graphene oxide films after chemical treatments by X-ray photoelectron and micro-Raman spectroscopy. Carbon 47 (2009) 145-152.

[72] Y. Sun, X. Hu, W. Luo, Y. Huang, Ultrafine $\mathrm{MoO}_{2}$ nanoparticles embedded in carbon matrix as a high-capacity and long-life anode for lithium-ion bateries. J. Mater. Chem. 22 (2012) 425-431.

[73] M. Chen, J. Liu, W. Zhou, J. Lin, Z. Shen, Nitrogen-doped graphene-supported transitionmetals carbide electrocatalysts for oxygen reduction reaction. Sci. Rep. 5 (2015) 10389-10399.

[74] A. Bhaskar, M. Deepa, T.N. Rao, $\mathrm{MoO}_{2} /$ multiwalled carbon nanotubes (MWCNT) hybrid for use as a Li-Ion Battery Anode. ACS Appl. Mater. Interfaces. 5 (2013) 2555-2566.

[75] P. Kaiser, R.B. Unde, C. Kern, A. Jess, Production of liquid hydrocarbons with $\mathrm{CO}_{2}$ as carbon source based on reverse water-gas shift and Fischer-Tropsch synthesis. Chem. Ing. Tech. 85 (2013) 489-499.

[76] S.-G. Wang, D.-B. Cao, Y.-W. Li, J. Wang, H. Jiao, $\mathrm{CO}_{2}$ reforming of $\mathrm{CH}_{4}$ on $\mathrm{Ni}(111)$ : A density functional theory calculation. J. Phys. Chem. B 110 (2006) 9976-9983.

[77] A.H. Zhang, J. Zhu, W.H. Duan, Study of dissociation barriers of $\mathrm{H}_{2}$ on $\mathrm{Ni}(111)$ and $\mathrm{Ni}_{3} \mathrm{Fe}(111)$. Phys. B 393 (2007) 223-227. 
[78] L.F. Bobadilla, J.L. Santos, S. Ivanova. J.A. Odriozola, A. Urakawa Unravelling the role of oxygen vacancies in the mechanism of the reverse Water-Gas Shift reaction by operando DRIFTS and Ultraviolet-Visible Spectroscopy. ACS Catal. 2018, 88, 7455-7467. 